\title{
Movements in the Equity Premium
}

REAL BOND RATES increased sharply in the early 1980 s and have remained high since. Even today, in the midst of a world recession and low U.S. and Japanese short real rates, long real rates throughout the world remain unusually high. Pessimists trace the high rates to a decrease in the supply of capital. They point to the long string of fiscal deficits and to the decline in household saving and warn of the disappearance of thrift. Optimists trace the high rates to an increase in the demand for capital and point to the high profit opportunities unleashed by the conservative revolutions of the 1980s.

These factors have surely played a role. But there is more at work, for consider the following fact: while expected real rates on bonds have indeed been high for more than a decade, expected real rates of return on stocks appear, if anything, to have declined slightly. This suggests that the focus should not only be on the increase in bond rates, but also on the simultaneous increase in bond rates and decrease in equity rates: on the decrease in the equity premium. This is the focus of this paper.

In the first section, I construct expected real rates on short- and medium-term bonds for a number of OECD countries from 1978 on, using commercial forecasts of inflation available at the time. I stop short of constructing expected real rates of return on stocks, but by looking at the underlying components, I argue that the 1980s were indeed associated with a sharp decrease in the equity premium.

I thank Antonio Spilimbergo and Owen Lamont for their excellent research assistance. I thank Data Resources Inc. for their forecasts. I have benefited from many comments on an earlier version of this paper. In particular, I thank Andy Abel, Tony Atkinson, Ricardo Caballero, John Campbell, Stanley Fischer, John Heaton, Greg Mankiw, James Poterba, Ned Phelps, Julio Rotemberg, Paul Samuelson, Lawrence Summers, and Sushil Wadwhani. I thank the National Science Foundation for financial support. 
Having reviewed the recent evidence, I turn in the second section to longer time series. This both provides a historical perspective and allows for the use of more sophisticated time-series techniques. Carefully constructed data with a long time sample exist for only a few countries. I limit myself to the United States since 1927, relying on the data constructed by Roger Ibbotson and associates. ${ }^{1}$ Using these data, I derive series for expected rates of return on bonds and stocks.

In the third section, I present and discuss the implied series for the equity premium. Movements in the premium since 1927 exhibit two major characteristics. The first is a long decline since the 1950 s from unusually high premiums in the late 1930s and 1940s. The second is movements around this trend that are clearly correlated with movements in inflation. This last relation is particularly clear in the last two decades. A high premium in the 1970s is associated with a sharp increase in inflation, while a low premium in the 1980 s is associated with a sharp decline in inflation.

In the fourth section, I focus on the low-frequency movements in the premium, especially on the postwar decline. I review plausible causes. Some, such as the evolution of government debt, can be clearly rejected. Long-lasting effects of the Great Crash on perceived volatility appear to be a good candidate for explaining the period of high premiums. The slow disappearance of those perceptions, as well as the increasing role of long-horizon investors such as pension funds, can explain the postwar decline.

In the fifth section, I focus on higher-frequency movements and on the role of inflation on the premium and its components. This is muchtraveled ground, and while I provide my own econometric estimates, I also relate the results to past research. My first conclusion is that expected inflation leads to a decrease in medium- and long-term real bond rates-but only for a few years, at most. My second conclusion is that expected inflation leads to an increase in the rate of return on stocks. Thus, lower inflation leads to a lower premium, with effects that appear to be larger in the short run than in the long run.

The trend of the postwar decline in the equity premium and the prospects of low inflation in the United States today both imply that the equity premium is likely to remain small. The sixth section explores the potential macroeconomic implications of these findings.

1. Ibbotson Associates (1992). 


\section{Returns on Bonds and Stocks since 1978}

I construct real bond rates by defining them as

$$
E R^{n}(t)=I^{n}(t)-E A \pi^{n}(t),
$$

where

$$
A \pi^{n}(t) \equiv\left[(1-\delta) /\left(1-\delta^{n}\right)\right] \sum_{i=0}^{n-1} \delta^{i} E \pi(t+i) .
$$

$I^{n}(t)$ is the yield to maturity at time $t$ on a coupon bond of maturity $n$, and $E R^{n}(t)$ is the expected real rate on that bond. The expected real rate is equal to the nominal rate minus the expected value of a weighted average of inflation, $\pi$, over the life of the bond ( $A$ is a mnemonic for annuity value, a term that I use for convenience, although it is not quite right given that these are bonds of finite maturity). Weights on future inflation sum to one and decline at rate $\delta$, where $\delta$, the discount rate, is given by $\delta=(1+\bar{I})^{-1}$, with $\bar{I}$ the average nominal rate.

I construct real rates for both short-term bonds (bonds with a maturity of one quarter) and for medium-term bonds (bonds with a maturity of close to five years). Sources and the exact nature of the bonds are given in the appendix, in tables A1 and A2. In both cases, the only issue is to construct the empirical counterpart to the last term in equation 1 . In this section, my strategy is to rely on forecasts of inflation available as of the time the bonds were held. Forecasts over the relevant horizon are available from Data Resources Inc. (DRI) since 1978 for six major OECD countries: the United States, the United Kingdom, Germany, France, Italy, and Japan. For each of those countries, I construct a short-term and a medium-term real rate, using the relevant nominal rate for the first month of each year, and the constructed value of $E A \pi^{n}$, based on DRI forecasts as of December of the previous year. Constructed real rates for each year and each country, as well as sources and details of construction, are given in tables A1 and A2.

The results are summarized in figures 1 and 2. Figure 1 presents the evolution of the "world" short-term real rate since 1978. The world rate is constructed using relative GDP at current exchange rates as relative weights. In 1992, those weights were 41 percent for the United States, 25 percent for Japan, 11 percent for Germany, 9 percent for France, 7 percent for Italy, and 6 percent for the United Kingdom. (The weights 
Figure 1. World Short-Term Real Interest Rate, 1978-93

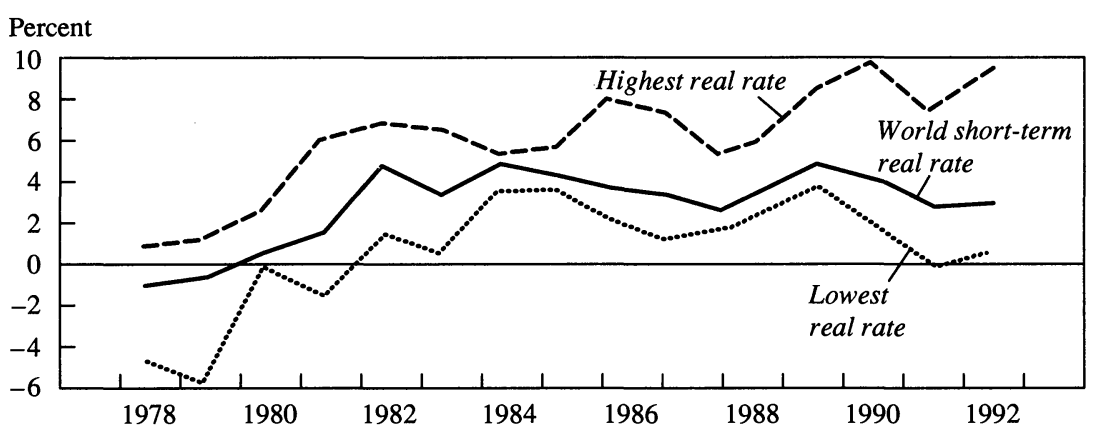

Source: Author's calculations as described in appendix table A1.

a. The dashed lines indicate the lowest and highest short-term real rates in each year across the United States, the United Kingdom, France, Italy, Japan, and Germany.

for 1993 are assumed to be the same as for 1992.) In addition, to give a sense of the dispersion of rates across countries, the lower and upper lines give the lowest and highest short-term real rates in each year. Figure 2 does the same for the world medium-term real rate. Japan is excluded because forecasts were not available for the entire period over the relevant horizon; the weights of other countries are correspondingly adjusted.

Figures 1 and 2 present a familiar picture. They show a sharp increase in both short- and medium-term rates in the early 1980s. The short-term rate climbed from -1.0 percent in 1978 to 4.9 percent in 1984 , while the medium-term rate increased from 2.1 percent in 1978 to 6.3 percent in 1982 . Both rates have declined gradually since the mid-1980s. At the beginning of 1993, the short-term real rate stood at 2.8 percent, while the medium-term real rate was 3.5 percent. Rates have declined a bit further since the beginning of the year.

These numbers can be compared to the numbers for the only large market where real rates are directly observable: the U.K. indexed bond market. Indexed bonds have existed since 1982 in the United Kingdom. There are a few caveats in using yields on those bonds, from the small initial size of the market to a number of tax issues. ${ }^{2}$ But for my purposes, the tax correction is easy to make. Consider first the raw numbers. Real rates on five-year indexed bonds were equal to 2.2 percent in the first

2. See Woodward (1990). 
Figure 2. World Medium-Term Real Interest Rate, 1978-93 ${ }^{\text {a }}$

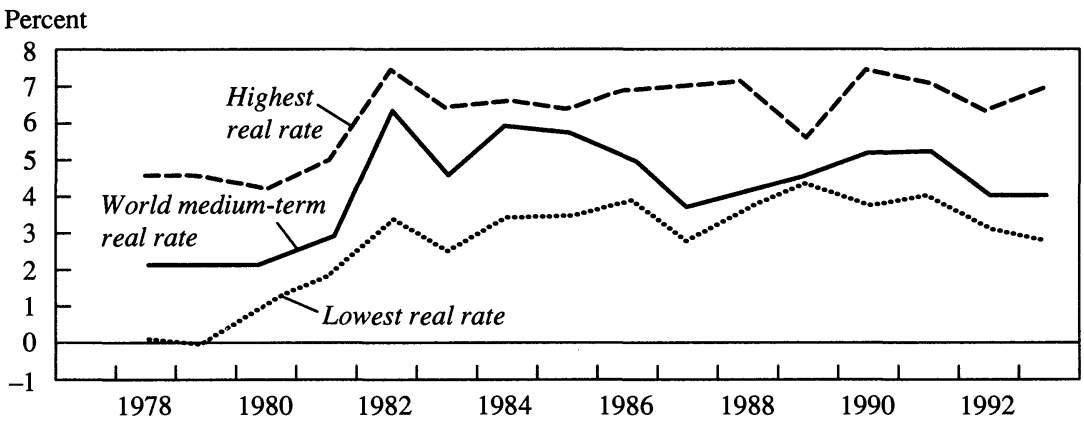

Source: Author's calculations as described in appendix table A2.

a. The dashed lines indicate the lowest and highest short-term real rates in each year across the United States, the United Kingdom, France, Italy, and Germany.

quarter of 1983 , increasing to 4.5 percent in 1986 ; in the first quarter of 1993, they stood at 3.5 percent. Tax considerations suggest that this rate should be adjusted by adding $[\tau /(1-\tau)] \pi$ to it before comparing it to the real rates derived from looking at nominal bonds, where $\tau$ is the tax rate. ${ }^{3}$ Thus, taking $\tau=0.2$, the value suggested by G. Thomas Woodward, and $\pi=4.0$ percent, each number above must be increased by 1 percentage point. They can be compared to the numbers given in the appendix for the U.K. medium-term real rate: 2.3 percent for $1983,6.7$ percent for 1986, and 3.1 percent for 1993.

\section{Real Rates of Return on Stocks}

What I have constructed for bonds are in effect expected real internal rates of return over the relevant horizons: three months for short rates, and around five years for medium-term rates. Given my goal of computing an expected equity premium, I should ideally compare them to the corresponding rates for stocks: expected real internal rates of return for stocks over holding periods of three months and five years. Constructing such expected real internal rates, however, requires forecasts of stock

3. The reason is as follows: coupon payments are taxed, but capital gains are not. Let $i$ be the nominal rate on a nominal bond, $r$ be the real rate on an indexed bond, and $\pi$ be inflation. Then, assuming arbitrage, $i(1-\tau)-\pi=r(1-\tau)$. Define $r_{b}=i-\pi$ to be the implicit real rate on a nominal bond. Then, $r_{b}=r+[\tau /(1-\tau)] \pi$. 
price changes over the relevant holding periods. Such forecasts are typically not available, and even if they were, I would be reluctant to use them. ${ }^{4}$

Thus, I focus on the rate of return that investors can expect to get if they hold the stock forever. In that case, the expected real rate of return depends only on the current price and the sequence of expected future dividends. Stated roughly, it is equal to the dividend yield plus the expected long-run growth rate of real dividends. Thus, as the dividend yield can be observed, all that is needed to construct estimates of the rate of return is an estimate of long-run real dividend growth, a task that is easier than forecasting capital gains. While this formally gives only the rate of return one can expect by holding stocks forever, it is likely to be a good approximation to expected rates of return over finite but sufficiently long horizons-say, five years or more.

More formally, I define the expected real rate of return on stocks at time $t, E R_{s}(t)$, as

$$
E R_{s}(t)=E[D(t) / P(t)]+E A g_{d}(t),
$$

where

$$
\text { (4) } E A g_{d}(t) \equiv[(r-g) /(1+r)] \sum_{i=0}^{\infty}[(1+g) /(1+r)]^{i} E g_{d}(t+i+1) \text {. }
$$

The ratio of real dividends over period $t$ to the real stock price at time $t$ is $D(t) / P(t)$. While $P(t)$ is known at time $t, D(t)$ is not; this is why the first term is the expected dividend-price ratio over period $t$ as of time $t$. The term $g_{d}(t)$ denotes the growth rate of dividends in period $t$, defined as the ratio of real dividends in period $t$ to real dividends in period $t-1$, minus one. $A g_{d}(t)$ is the "long-run growth rate of dividends," given by the annuity value of the growth rate of future dividends. The parameters $g$ and $r$ are the mean rates of growth of real dividends and the mean real rate of return on stocks, respectively.

The equation is a dynamic extension of Gordon's formula, which was initially derived for the case of constant dividend growth. ${ }^{5}$ It is useful,

4. The Livingston survey gives, for the United States, a median forecast of the oneyear rate of change of the S\&P index for each year since 1957. These forecasts are typically very high, with a mean value of about 22 percent in the 1970 s. They steadily decline in the 1980s, from 21 percent in 1979 to 1 percent in 1990. Taken at face value, these reinforce the case that the equity premium decreased drastically in the 1980s. But I doubt that these numbers capture the expectations of actual investors in the stock market.

5. Gordon (1962). 
Figure 3. World Dividend-Price Ratio, 1978-92 ${ }^{\text {a }}$

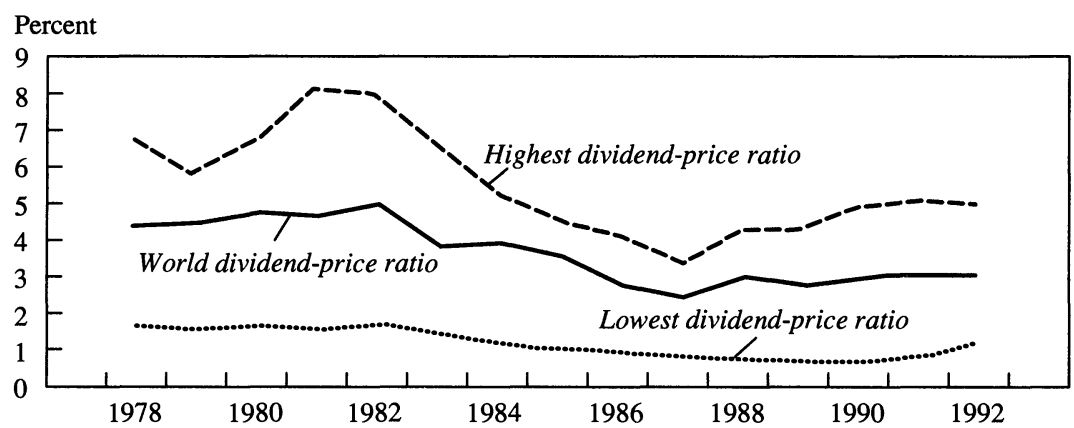

Source: Author's calculations as described in appendix table A3.

a. The dashed lines indicate the lowest and highest dividend-price ratios in each year across the United States, the United Kingdom, France, Italy, Japan, and Germany.

for later use, to sketch its derivation. Denote the one-year realized rate of return on stocks over period $t$ by $R_{s}^{1}(t)$. Then, by definition,

$$
1+R_{s}^{1}(t)=[D(t)+P(t+1)] / P(t) .
$$

Solving recursively forward, assuming that the dividend-price ratio does not explode, gives $P(t)$ as the present discounted value of future dividends, discounted by the sequence of $n$-year realized rates of return. Dividing both sides by $D(t)$, taking expectations conditional on information at time $t$, and linearizing, gives equation 3 , with $E R_{s}(t)$ defined as

$$
E R_{s}(t) \equiv[(r-g) /(1+r)] \sum_{i=0}^{\infty}[(1+g) /(1+r)]^{i} E R_{s}^{1}(t+i) .
$$

$E R_{s}(t)$ is thus a weighted average-more precisely, the annuity valueof current and expected future one-period real rates of return on stocks.

In this section, I shall not attempt to construct series for $E D / P$ or for $E A g_{d}$, leaving this to later sections where I can use longer time series and appropriate time-series techniques. But even an informal examination of the data yields clear conclusions.

Figure 3 gives the evolution of the world dividend yield since 1978 . The method of construction parallels that used for interest rates. The world dividend yield is a weighted average of dividend yields in the major stock market of each of the six countries. The dividend yields in each country are yearly averages. The weights are, for consistency with interest rates, relative GDP weights; using relative stock market capitaliza- 
Figure 4. Growth of World Real Dividends per Share, 1978-92

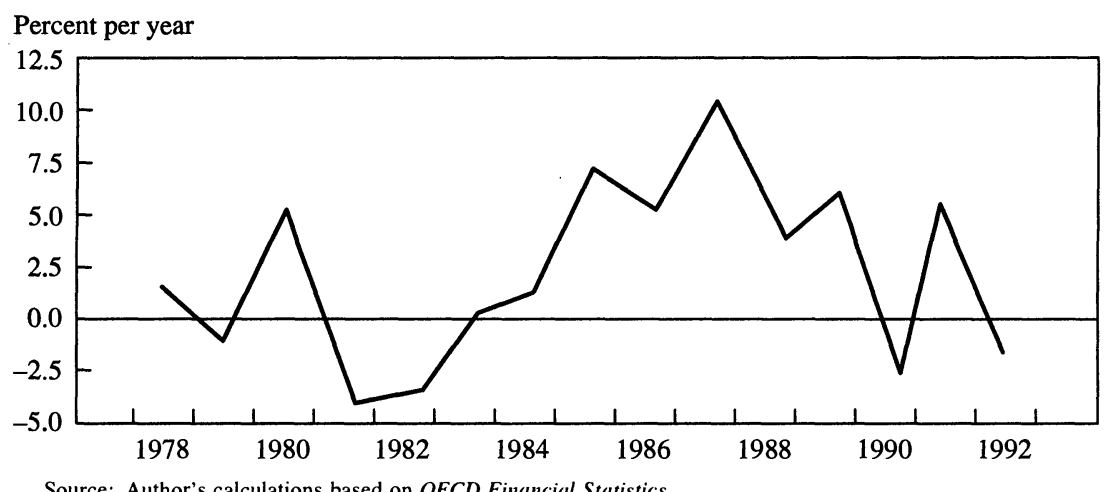

Source: Author's calculations based on $O E C D$ Financial Statistics.

tions leads to weights that are not very different. To give a sense of the heterogeneity of experiences across countries, the figure presents two bands, corresponding to the highest and the lowest dividend yields for each year. Sources and dividend yields for each year and each country are given in appendix table A3.

The main characteristic of the figure is quite striking. From 1978 to 1982 , the dividend yield increased slightly, from 4.4 percent to 5.0 percent. But from 1982 to 1992 , it has declined from 5.0 percent to 2.8 percent. Put another way, since 1982, while real dividends have increased by 34 percent, real stock prices have increased by close to 91 percent. One may worry that this reflects the evolution of one or two marketsin particular, the gyrations of the Japanese market. ${ }^{6}$ This is not the case. The decline is strong in all countries, with the exception of Italy (Milan), where the dividend yield has increased. This similarity shows up in the fact that the bands have remained roughly parallel to the mean since 1982.

The next question is whether the decrease in the dividend yield has been offset by expectations of higher long-run dividend growth: that is, of a higher value of $E A g_{d}$. Figure 4 plots the evolution of $g_{d}$, the annual growth rate of world real dividends per share from 1978 to 1992. It shows

6. For a discussion of the evolution of dividends, earnings, and prices in Japan, see French and Poterba (1991). 
large movements in the growth rate that closely follow the evolution of world output during the period. Dividend growth is negative in the early 1980 s, reflecting the world recession; high in the mid-1980s, reflecting the world expansion; and low again in the early 1990s. Can movements in expected long-run dividend growth explain the different evolution of real bond rates and dividend yields over the period? At this point, it is useful to carry out a simple algebraic exercise.

For purposes of computation, define the equity premium as the difference between the expected rate of return on stocks and the expected rate of return on medium-term bonds. From the definitions of $E R_{s}$ and $E R^{5}$ above, the equity premium is thus given by

$$
E X \equiv\left(E R_{s}-E R^{5}\right)=\left(E D / P+E A g_{d}\right)-E R^{5}
$$

Thus, over any period of time, the change in the premium is given by

$$
\Delta E X=\Delta(E D / P)+\Delta\left(E A g_{d}\right)-\Delta\left(E R^{5}\right) .
$$

Leaving aside for the moment the last few years, consider the 1980s. In 1980, the world medium-term real bond rate was equal to 2.0 percent; in 1990 , it stood at 4.8 percent. In 1980 , the world dividend yield was equal to 4.7 percent; in 1990 , it stood at 2.8 percent. Thus, to argue that there was no change in the equity premium, one must argue that the underlying expected rate of growth of real dividends was roughly 4.7 percent higher in 1990 than in 1980. Is this reasonable?

The answer is clearly no. A simple approach here is to think about the underlying determinants of dividend growth, the ratio of dividends to earnings, and the growth rate of earnings. The world pay-out ratio-the ratio of dividends to earnings-has hovered between 0.4 and 0.5 , but shows no trend over the last twenty years. And, while the share of profits increased in the 1980s, no further large changes are forecast. ${ }^{7}$ The working assumption must be that profits will grow at the same rate as the

7. A partial mea culpa is needed here. Writing in the early 1980 s with Lawrence Summers (Blanchard and Summers, 1984), we suggested that part of the divergence between dividend yields and real bond rates may come from anticipations of higher profit rates. Indeed, there was an increase in profit rates, and thus a transitory increase in growth rates of real profits, in the 1980s. Whatever the merits of the hypothesis then, they have largely disappeared. There is little reason to expect a further large increase in the share of profits, and dividend yields have not returned to their previous values. 
economy. Here, as is well known, trend growth appears to have decreased, not increased. ${ }^{8}$ Putting things together, it is very unlikely that expected dividend growth in 1990 was much higher than it was ten years earlier. Thus, it seems difficult to avoid the conclusion that there was a sharp decrease in the equity premium in the $1980 \mathrm{~s}^{9}$

What about the 1990s? Dividend yields have remained roughly constant since 1990, but medium-term real rates have declined, from 4.9 percent in 1991 to 3.5 percent in early 1993. They have further decreased over the course of 1993 . These numbers suggest that the equity premium has increased, but not to its 1980 level. I return to this issue later.

\section{U.S. Bond and Stock Returns since 1927}

The decrease in the premium in the 1980s must be placed in historical perspective. Was the equity premium in early 1980 unusually high to start with? How unusual is a low premium? To gain historical perspective, I turn to longer data. Ibbotson and associates have put together an appropriate data set for the United States since 1927. I shall rely on it. ${ }^{10}$

8. Ned Phelps has suggested to me that this view may be too provincial. Multinational companies operate in a number of markets where growth may be expected to be high, from Asia to Mexico-perhaps even to eastern Europe. This suggests dividing firms in the stock market between those with such operations and those without, and looking for systematic differences in dividend yields. I have not done so.

9. The conclusion that the expected rate of return on stocks went down in the 1980s may strike some readers as hard to reconcile with the fact that the 1980 s were a time of booming stock markets and large realized capital gains. The key to reconciling both sets of facts is that I am looking at ex ante, or expected, rates of return, whereas the statement refers to ex post, or realized, rates of return. What I am arguing, in effect, is that most of those capital gains were indeed unexpected. A similar argument is developed by Malkiel (1990, p. 332), who also concludes that "at the end of the 1980's, bonds appeared to offer return possibilities almost as attractive as stocks, but with less risk."

10. An even longer data set, going back to the beginning of the nineteenth century, has been constructed by Jeremy Siegel (1992a, 1992b). The trade-off between the two data sets is between the length of the time series and the amount of change in the structure of markets. I was reluctant to use nineteenth century data, but I shall mention basic results from Siegel when relevant. Mullins and Wadhwani (1989) look at closely related issues using three centuries of U.K. data. But the quality of the data-in particular, the use of averages, and imprecise timing-prevents me from using them for the type of econometrics I do below. 


\section{Medium-Term and Long-Term Real Bond Rates}

I consider two types of bonds: medium-term bonds, with a maturity of five years; and long-term bonds, with a maturity of twenty years. Both are from Ibbotson and are available annually for 1927-93. The corresponding five-year and twenty-year real rates are given, as before, by equation 1 , with $n=5$ and $n=20$. In both cases, I construct expected annuity values of inflation as follows.

I first construct the ex post, realized annuity value $A \pi^{n}(t)$, using the definition in equation 2. Inflation in year $t, \pi_{t}$, is constructed as the change in the Consumer Price Index (CPI) from December of year $t-1$ to December of year $t$. Constructing $A \pi^{n}(t)$ requires two assumptions. The first is the choice of the discount rate, $\delta$. Because the nominal rate moves so much during that period, the appropriate discount factor varies from a value close to zero during World War II to a value close to 0.13 in the 1970s. I use $\delta=0.10$. Results below are not sensitive to values of $\delta$ between 0.0 and 0.10 . The second assumption comes from the fact that, to construct $A \pi^{n}$ for the last $n-1$ years of the sample, an assumption is needed for the value of $\pi(t)$ after the end of the sample. I assume that inflation in 1993 and beyond will equal its 1992 value; this seems reasonable and consistent with current forecasts. The results below are not sensitive to reasonable choices of this terminal value.

I then regress $A \pi^{n}(t)$ on information available at time $t$ and construct $E A \pi^{n}(t)$ as the fitted value. Because only part of the information set can be included in the regression, the resulting estimated series is not equal to the true expectation-even under rational expectations-but the difference between the two is uncorrelated with the variables included in the regression. ${ }^{11}$

A choice must be made about which variables to include. Two obvious variables are lagged inflation, and lagged nominal rates, which are likely to contain information about current and future inflation, or may affect inflation causally. Because I look at stock returns later, I include

11. Under some hypotheses, the asset prices may be sufficient statistics for the information available to investors. Under the hypothesis that the real rate of return on bonds is constant, nominal rates are a sufficient statistic for information about future inflation. But these hypotheses, as will be clear in this paper, are strongly rejected. For further discussion, see Campbell and Shiller (1987). 
two other variables, the dividend yield and the lagged real rate of capital gain on stocks.

The exact regressions are as follows. The left-hand-side variables are either $A \pi^{5}(t)$ for five-year bonds or $A \pi^{20}(t)$ for twenty-year bonds. The right-hand-side variables, which are known at the beginning of year $t$, are:

$\pi(t-1)$, the rate of inflation for year $t-1$, defined as the December CPI for year $t-1$ divided by the December CPI for year $t-2$, minus one.

Either $I^{5}(t)$ or $I^{20}(t)$, as the case may be, defined as the nominal yields at the beginning of year $t$, constructed as the end of December $t-1$ values of those nominal yields.

$D(t-1) / P(t-1)$, the dividend yield for year $t-1$, defined as real dividends over year $t-1$, divided by the real stock price index at the beginning of year $t-1$. Real dividends, $D(t-1)$, are constructed as nominal dividends paid over year $t-1$, deflated by the average CPI for year $t-1$. The real stock price, $P(t-1)$ is constructed as the nominal stock price at the end of year $t-2$, deflated by the December CPI for year $t-2$.

$g_{p}(t-1)$, the rate of real capital gain over year $t-1$, constructed as $P(t) / P(t-1)-1$.

As has been documented by many, including Robert B. Barsky, the inflation process has not been stable over the period 1927-93; there is substantially more persistence now than there was earlier. ${ }^{12}$ This subsample instability cannot be ignored and turns out to be important for a number of results below. To deal with it, I use rolling regressions. ${ }^{13}$ Thus, to estimate $E A \pi^{n}(t)$, I use the fitted value from a regression of $A \pi^{n}(t)$ on the four variables over the sample composed of the previous forty observations, $t-39$ to $t$. More specifically, the fitted values of $A \pi^{n}(t)$ for $t=1929$ to 1968 are obtained from a regression run from 1929 to 1968 . Thereafter $A \pi^{n}(t)$ is obtained from regressions over $t-39$ to $t$, for $t=1969$ to 1993 .

12. Barsky (1987).

13. Rolling regressions may not be appropriate if the inflation process changes drastically but infrequently. For evidence on the inflation process along these lines, see Evans and Lewis (1993). 
Table 1. Regressions of Inflation, Five-Year Horizons ${ }^{a}$

\begin{tabular}{|c|c|c|c|c|c|c|}
\hline \multirow[b]{2}{*}{ Period } & \multirow[b]{2}{*}{ Equation } & \multicolumn{4}{|c|}{ Independent variable } & \multirow[b]{2}{*}{$\bar{R}^{2}$} \\
\hline & & $\begin{array}{l}\text { Dividend } \\
\text { yield }\end{array}$ & $\begin{array}{l}\text { Real } \\
\text { capital } \\
\text { gain } \\
\text { rate }\end{array}$ & $\begin{array}{l}\text { Nominal } \\
\text { five- } \\
\text { year } \\
\text { yield }\end{array}$ & $\begin{array}{l}\text { Inflation } \\
\text { rate }\end{array}$ & \\
\hline \multirow[t]{3}{*}{ 1929-93 } & $1-1$ & $\ldots$ & $\ldots$ & $\ldots$ & $\begin{array}{l}0.47 \\
(3.7) \\
{[0.0]}\end{array}$ & 0.32 \\
\hline & $1-2$ & $\ldots$ & $\ldots$ & $\begin{array}{c}0.01 \\
(0.1)\end{array}$ & $\begin{array}{l}0.47 \\
(3.3) \\
{[0.0]}\end{array}$ & 0.31 \\
\hline & $1-3$ & $\begin{array}{c}-0.27 \\
(-0.8)\end{array}$ & $\begin{array}{c}0.00 \\
(0.7)\end{array}$ & $\begin{array}{c}-0.03 \\
(-0.2)\end{array}$ & $\begin{array}{l}0.48 \\
(3.5) \\
{[0.0]}\end{array}$ & 0.29 \\
\hline \multirow[t]{3}{*}{ 1954-93 } & $1-4$ & $\ldots$ & $\ldots$ & $\ldots$ & $\begin{array}{l}0.55 \\
(2.8) \\
{[0.0]}\end{array}$ & 0.37 \\
\hline & $1-5$ & $\cdots$ & $\ldots$ & $\begin{array}{c}-0.32 \\
(-1.3)\end{array}$ & $\begin{array}{l}0.80 \\
(3.2) \\
{[0.0]}\end{array}$ & 0.40 \\
\hline & $1-6$ & $\begin{array}{c}-0.98 \\
(-1.9)\end{array}$ & $\begin{array}{c}0.04 \\
(1.8)\end{array}$ & $\begin{array}{l}-0.33 \\
(-1.6)\end{array}$ & $\begin{array}{l}0.96 \\
(3.5) \\
{[0.0]}\end{array}$ & 0.42 \\
\hline
\end{tabular}

Source: Author's regressions based on data from Ibbotson Associates (1992) and U.S. Bureau of Labor Statistics, Consumer Price Index.

a. The dependent variable, $A \pi^{5}$, is the realized value of inflation over the next five years, as described in the text. Numbers in parentheses are $t$-statistics associated with the null hypothesis that the coefficient or sum of coefficients is zero. Numbers in brackets show the significance level of the test that the set of coefficients is equal to zero. The second moments are Newey-West corrected.

b. The dividend yield and the real capital gain rate are lagged once. Inflation is entered with three lags; the number reported for inflation is the sum of the coefficients.

To conserve on degrees of freedom, I allow for only one lag of each variable, except inflation, which I allow for three lags. I allow for more lags on inflation not because they are needed, but because I want to focus later on the dynamic effects of inflation. All the results emphasized below are robust to the inclusion of more lags on the other variables.

Tables 1 and 2 summarize the regression results for $A \pi^{5}$ and $A \pi^{20}$, respectively. The results are reported for the whole sample (which is never used to construct the EAs but summarizes the information in a convenient way) and for the last rolling sample used, 1954-93. As a way of summarizing information, the tables also present regressions that in- 
Table 2. Regressions of Inflation, Twenty-Year Horizons ${ }^{a}$

\begin{tabular}{|c|c|c|c|c|c|c|}
\hline \multirow[b]{2}{*}{ Period } & \multirow[b]{2}{*}{ Equation } & \multicolumn{4}{|c|}{ Independent variable ${ }^{\mathrm{b}}$} & \multirow[b]{2}{*}{$\bar{R}^{2}$} \\
\hline & & $\begin{array}{l}\text { Dividend } \\
\text { yield }\end{array}$ & $\begin{array}{c}\text { Real } \\
\text { capital } \\
\text { gain } \\
\text { rate }\end{array}$ & $\begin{array}{c}\text { Nominal } \\
\text { twenty- } \\
\text { year } \\
\text { yield }\end{array}$ & $\begin{array}{c}\text { Inflation } \\
\text { rate }\end{array}$ & \\
\hline \multirow[t]{3}{*}{ 1929-93 } & $2-1$ & $\ldots$ & $\cdots$ & $\ldots$ & $\begin{array}{l}0.17 \\
(2.2) \\
{[0.12]}\end{array}$ & 0.10 \\
\hline & $2-2$ & $\ldots$ & $\ldots$ & $\begin{array}{r}0.10 \\
(0.7)\end{array}$ & $\begin{array}{l}0.13 \\
(1.3) \\
{[0.12]}\end{array}$ & 0.11 \\
\hline & $2-3$ & $\begin{array}{l}-0.57 \\
(-2.1)\end{array}$ & $\begin{array}{r}0.01 \\
(1.1)\end{array}$ & $\begin{array}{r}0.01 \\
(0.2)\end{array}$ & $\begin{array}{l}0.15 \\
(1.7) \\
{[0.10]}\end{array}$ & 0.22 \\
\hline \multirow[t]{3}{*}{$1954-93$} & $2-4$ & $\ldots$ & $\ldots$ & $\ldots$ & $\begin{array}{l}0.17 \\
(2.3) \\
{[0.00]}\end{array}$ & 0.09 \\
\hline & $2-5$ & $\cdots$ & $\ldots$ & $\begin{array}{c}-0.28 \\
(-1.5)\end{array}$ & $\begin{array}{l}0.40 \\
(4.8) \\
{[0.00]}\end{array}$ & 0.17 \\
\hline & $2-6$ & $\begin{array}{l}-1.06 \\
(-2.3)\end{array}$ & $\begin{array}{c}0.02 \\
(1.4)\end{array}$ & $\begin{array}{r}-0.27 \\
(-3.1)\end{array}$ & $\begin{array}{l}0.53 \\
(5.1) \\
{[0.00]}\end{array}$ & 0.46 \\
\hline
\end{tabular}

Source: See table 1 .

a. The dependent variable, $A \pi^{20}$, is the realized value of inflation over the next twenty years, as described in the text. Numbers in parentheses are $t$-statistics associated with the null hypothesis that the coefficient or sum of coefficients is zero. Numbers in brackets show the significance level of the test that the set of coefficients is equal to zero. The second moments are Newey-West corrected.

b. The dividend yield and the real capital gain rate are lagged once. Inflation is entered with three lags; the number reported for inflation is the sum of the coefficients.

clude only a subset of the four variables. While none of these regressions has a structural interpretation, they have three interesting features.

The first is the set of coefficients on past inflation in the regressions that include only past inflation. While the sum of coefficients on past inflation tends to be higher at the end of the sample, it is substantially below one. Using the whole sample regressions, an increase of 1 percent in past inflation leads to a revision of $A \pi^{5}$ of 0.47 percent, and of $A \pi^{20}$ of only 0.17 percent.

The second interesting feature is the coefficient on nominal rates in the regressions that include only past inflation and nominal rates. Under 
the hypothesis that the real rate is constant, the coefficient should be equal to one. But the coefficient is small, positive, and insignificant for the whole sample, and negative and marginally significant for the later part of the sample. ${ }^{14}$ This suggests large movements in the real rate, and/ or a systematic effect of inflation on real rates.

The third feature of interest is the coefficient of the dividend yield in the full regressions. Suppose that the stock market has more information about future inflation than just past inflation, and that anticipated inflation decreases prices given current dividends; one would then expect the coefficient of the dividend yield to be positive. It is in fact negative and usually significant, even if other variables are included in the regression.

The fitted values of expected inflation from regressions 1-3 and 2-3 of tables 1 and 2, and implied real medium-term and long-term rates are given in figures 5 to 8 . The fitted values of $A \pi^{5}$ and $A \pi^{20}$ are shown together with actual inflation in figure 5 . Actual inflation has two peaks in the 1940s-one during World War II, and one afterwards-and two peaks in the 1970s, corresponding to the two oil shocks. The two series for expected inflation smooth those peaks substantially. In 1980, with inflation at 12.5 percent, $A \pi^{5}$ stands at 9.7 percent-nicely fitting the value of 9.8 percent obtained from DRI forecasts, and used in the previous section-and $A \pi^{20}$ stands at 6.8 percent.

Figures 6 and 7 give the nominal yields and expected inflation for fiveyear and twenty-year bonds, respectively. The general characteristics are familiar. Note how five-year yields do not reflect the increase in inflation, actual and expected, during the war; how low real five-year rates become in the 1970s; and how large they are in the 1980s. The implied five-year real rates after 1978 are close to those derived in the first section using DRI forecasts and given in appendix table A1. The picture given in figure 7 is quite similar, although with real rates remaining more positive in the 1970 s.

Figure 8 plots the implied five-year and twenty-year real rates. The basic features are the negative real rates from the mid-1930s to the mid1950 s, the low rates again in the 1970 s, the high rates in the 1980 s, and their sharp decline again in the 1990s.

14. This specific subsample instability has been the topic of many papers. In a paper based on a postwar subsample, Fama (1975) found a coefficient of close to one in a regression of inflation on the short-term nominal rate. Later research has shown this result to be sample-specific. 
Figure 5. Actual Inflation, Five-Year Expected, and Twenty-Year Expected Inflation Rates, 1927-93

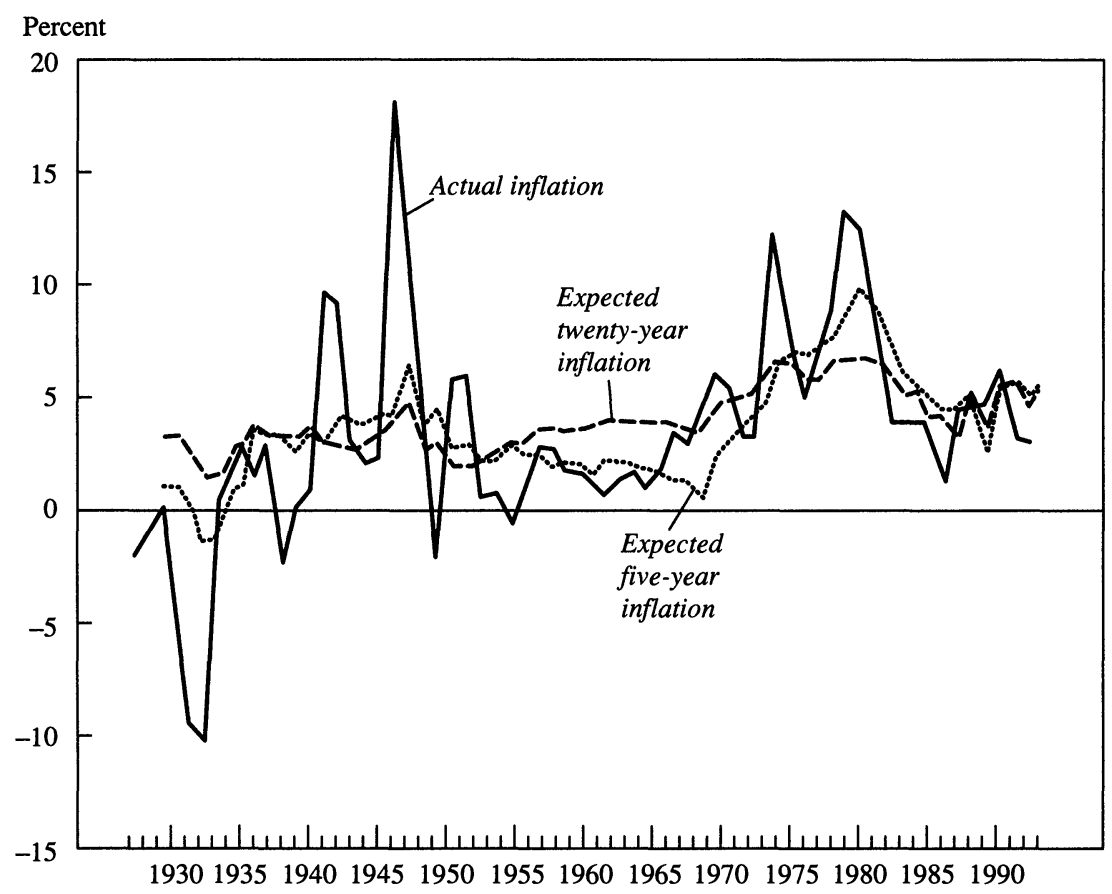

Source: Based on predicted values from regressions 1-3 and 2-3, tables 1 and 2 .

\section{Real Rates of Return on Stocks}

In constructing expected real rates of return on stocks, I start by following the same strategy as in the previous section, that of focusing on the expected rate of return from holding stocks forever. The approach to constructing $E R_{s}$ is conceptually similar to that used for bonds, namely the construction of actual values for $D / P$ and $A g_{d}$ based on equation 3 , and projection of those series on an information set to construct proxies for expected values.

I first construct the realized value of $A g_{d}(t)$, the annuity value of future growth rates of real dividends per share, where $g_{d}(t)$ is constructed as the ratio of real dividends $D(t)$ in year $t$ to real dividends in year $t-1$, minus one. To construct the required discount rate, I use the 
Figure 6. Five-Year Nominal Interest and Expected Inflation Rates, 1927-93

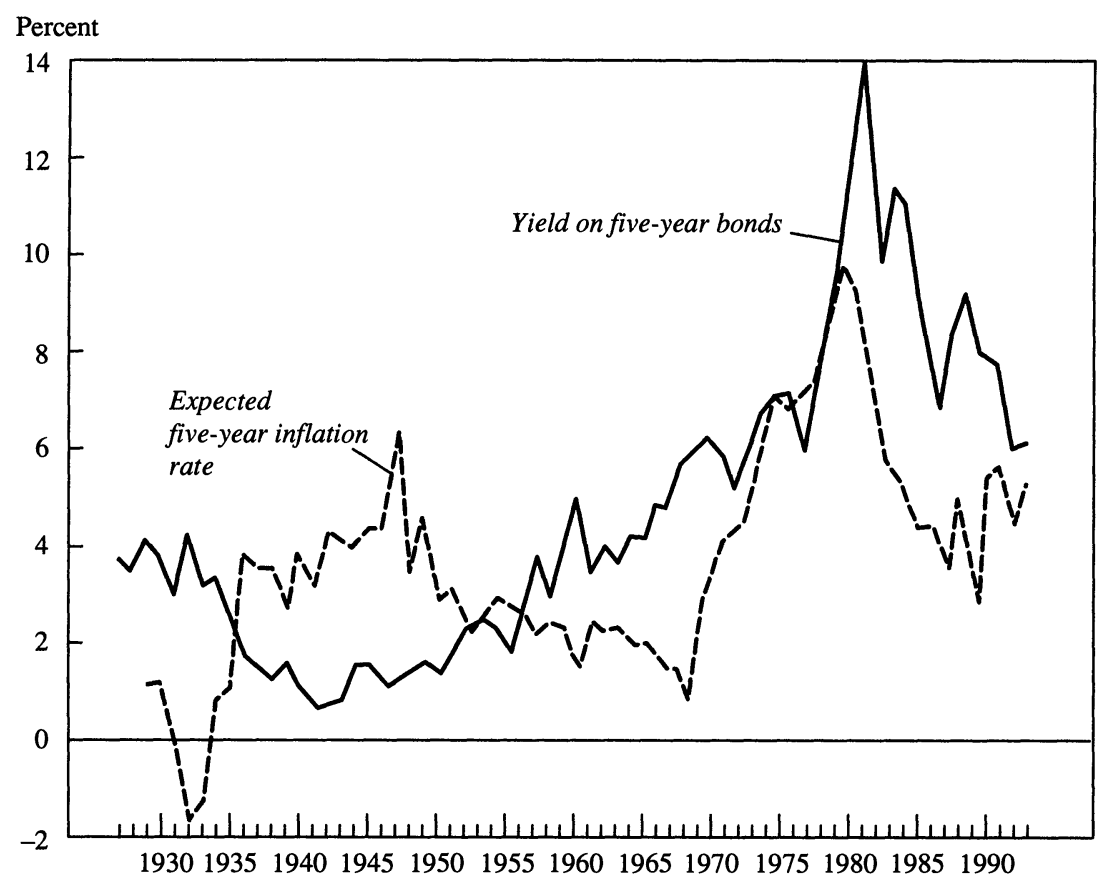

Source: Based on predicted values from equation 1-3 in table 1 and the five-year bond yield from Ibbotson (1992).

sample means as estimates of $g$ and $r$, namely 1.2 percent and 8.5 percent, which together imply a discount rate of 6.7 percent. As $A g_{d}$ is an infinite sum into the future, an assumption is needed for $g_{d}$ beyond 1992. I assume $g_{d}$ to be equal to its sample average-namely, 1.2 percentfrom 1993 forward. ${ }^{15}$ Again, results below are not sensitive to choices of the terminal condition, within, approximately 2 percent of the value I have chosen. ${ }^{16}$

15. Choosing the mean over a more recent period makes little difference. The mean value of $g_{d}$ is 1.3 percent for 1954-92 and 1.3 percent for 1980-92.

16. Implications of the choice of a terminal condition were discussed at length in the context of Robert Shiller's construction of ex post prices in the stock market (Shiller, 1981). There is a close relation between Shiller's approach and that followed here. Shiller discounted future dividends at a constant rate and looked at the resulting price series in relation to actual prices. Instead, I compute the rate of return that makes the actual price consistent with the expected sequence of dividends. 
Figure 7. Twenty-Year Nominal Interest and Expected Inflation Rates, 1927-93

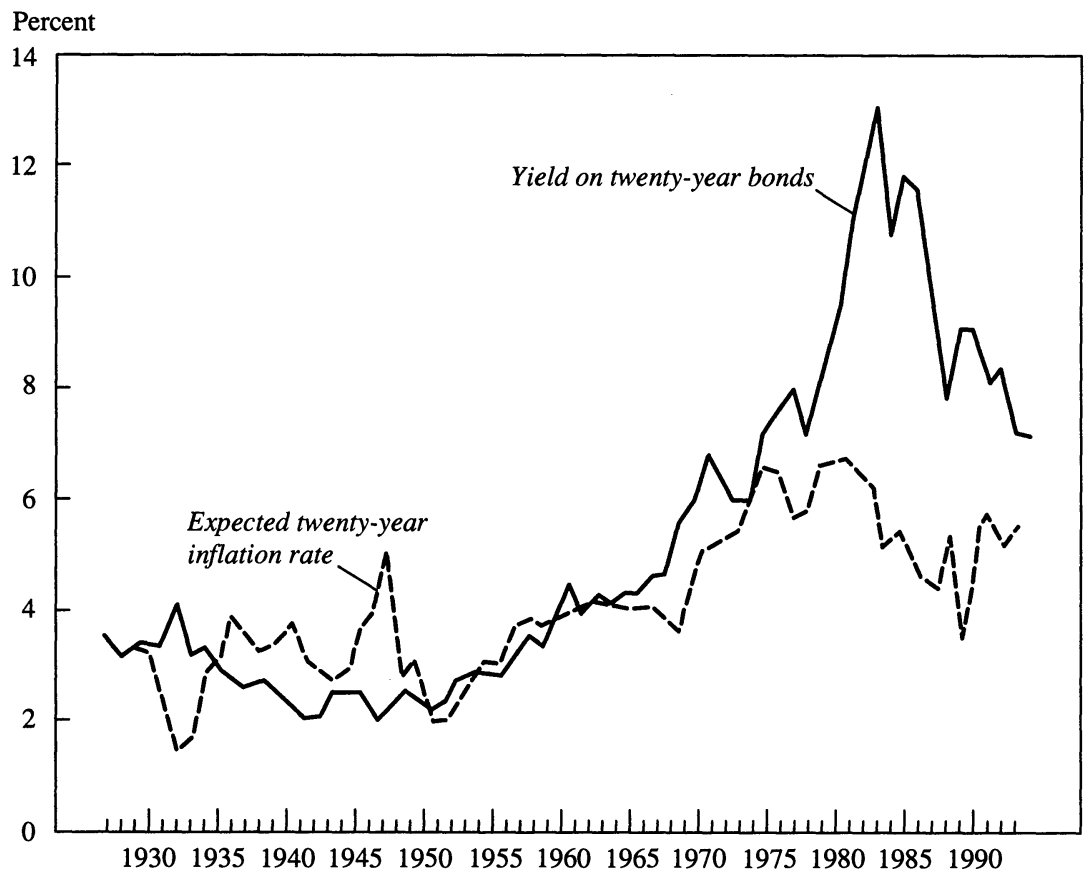

Source: Based on predicted values from equation 2-3 in table 2 and the twenty-year bond yield from lbbotson (1992).

I then regress both $D / P$ and $A g_{d}$ on the same four variables I used for bonds earlier. ${ }^{17}$ There is less evidence of subsample instability as for inflation earlier; however, for symmetry with the treatment of inflation, I also use rolling regressions based on forty years.

The results of the regressions are summarized in table 3. Again, these are reduced forms, not easily interpretable. But one result is of interest.

17. There are good reasons to think that the dividend payout ratio should help predict future dividend growth. Other things being equal, a lower payout should lead to higher dividend growth later. Thus, I also examined regressions including the payout ratio as an additional variable. The coefficient on the payout ratio is actually positive, and usually significant in most subsamples. But it is quantitatively small; an increase in the payout ratio from 0.6 (the sample average) to 0.7 leads to an increase in expected dividend growth of 0.3 percent. Including it in regressions makes little difference to the estimated series for expected dividend growth or the expected dividend yield. For those two reasons, and to conserve on degrees of freedom, I did not include it in the regressions. 
Figure 8. Five-Year and Twenty-Year Expected Real Interest Rates, 1929-93

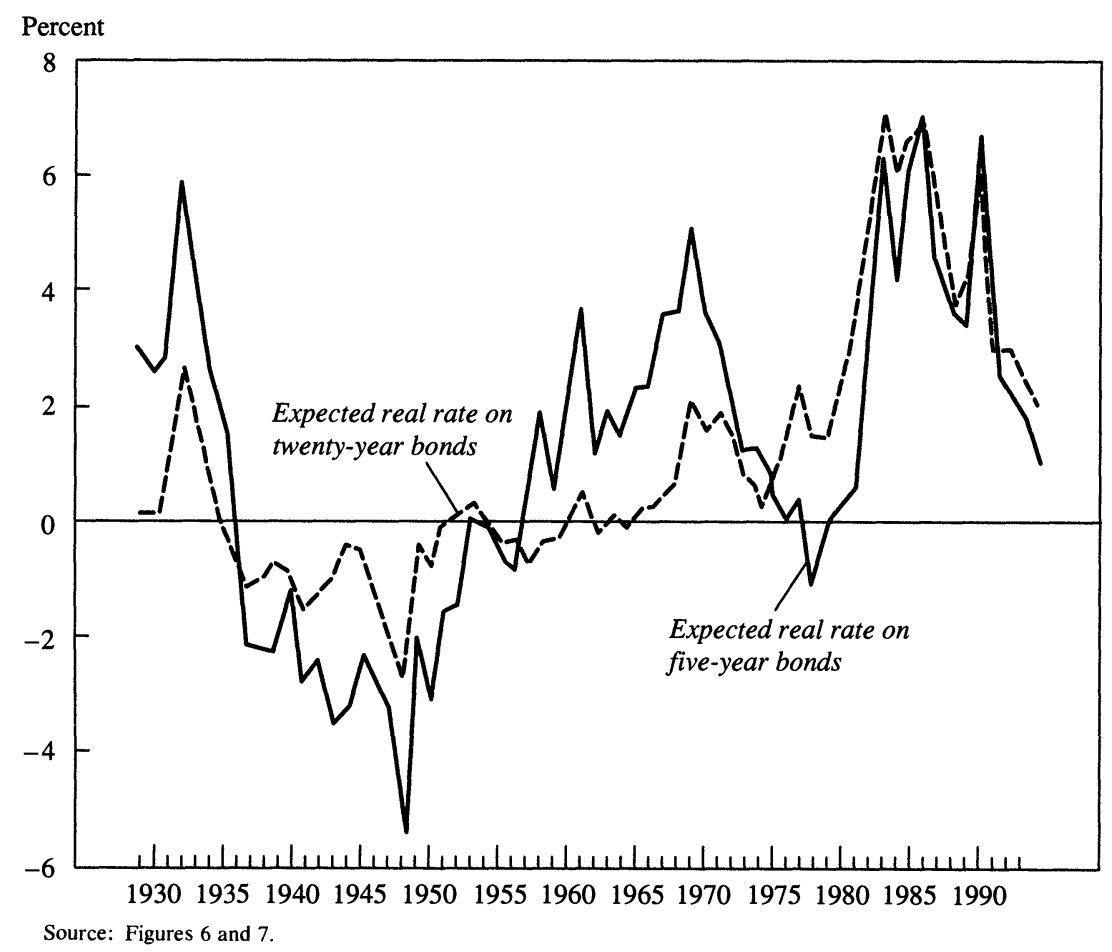

If most movements in the dividend yield reflected changes in the anticipated rate of growth of dividends, the coefficient in a regression of the realized growth of dividends on the dividend yield should yield a negative coefficient. Instead, the coefficient on the lagged dividend yield is positive and significant. This is true in regressions that include or exclude the other regressors. ${ }^{18}$

The regressions of both $D / P$ and $A g_{d}$ in table 3 imply, therefore, that a higher dividend yield leads to a higher expected rate of return on stocks, by leading both to a higher expected dividend yield next year,

18. A regression of the annual rate of growth of dividends, $g_{d}$, rather than the annuity value $A g_{d}$, yields a negative but insignificant coefficient on the lagged dividend yield, a sign consistent with the findings in Campbell and Shiller (1989, table 4). Thus, given the other variables in the regression, a higher dividend-price ratio predicts slower dividend growth in the short run, but higher dividend growth over the long run. 
Table 3. Regressions of the Growth Rate of Future Dividends and of the Dividend Yield ${ }^{\mathrm{a}}$

\begin{tabular}{|c|c|c|c|c|c|c|}
\hline \multirow[b]{2}{*}{$\begin{array}{c}\text { Dependent } \\
\text { variable }\end{array}$} & \multirow[b]{2}{*}{ Period } & \multicolumn{4}{|c|}{ Independent variable } & \multirow[b]{2}{*}{$\bar{R}^{2}$} \\
\hline & & $\begin{array}{l}\text { Dividend } \\
\text { yield }\end{array}$ & $\begin{array}{c}\text { Real } \\
\text { capital } \\
\text { gain rate }\end{array}$ & $\begin{array}{c}\text { Nominal } \\
\text { twenty- } \\
\text { year } \\
\text { yield }\end{array}$ & $\begin{array}{c}\text { Inflation } \\
\text { rate }\end{array}$ & \\
\hline \multirow{2}{*}{$\begin{array}{l}\text { Annuity } \\
\text { value of } \\
\text { growth rate } \\
\text { of real } \\
\text { dividends }\end{array}$} & 1929-93 & $\begin{array}{r}0.42 \\
(3.9)\end{array}$ & $\begin{array}{l}-0.007 \\
(-1.1)\end{array}$ & $\begin{array}{l}-0.05 \\
(-1.0)\end{array}$ & $\begin{array}{l}0.09 \\
(2.4) \\
{[0.04]}\end{array}$ & 0.25 \\
\hline & 1954-93 & $\begin{array}{c}0.50 \\
(3.9)\end{array}$ & $\begin{array}{l}-0.014 \\
(-1.8)\end{array}$ & $\begin{array}{r}0.07 \\
(1.4)\end{array}$ & $\begin{array}{c}-0.07 \\
(-1.3) \\
{[0.30]}\end{array}$ & 0.34 \\
\hline \multirow[t]{2}{*}{$\begin{array}{c}\text { Dividend } \\
\text { yield }\end{array}$} & 1929-93 & $\begin{array}{r}0.86 \\
(16.2)\end{array}$ & $\begin{array}{l}-0.030 \\
(-9.5)\end{array}$ & $\begin{array}{c}-0.05 \\
(-2.0)\end{array}$ & $\begin{array}{l}0.03 \\
(1.9) \\
{[0.03]}\end{array}$ & 0.85 \\
\hline & $1954-93$ & $\begin{array}{r}0.97 \\
(19.8)\end{array}$ & $\begin{array}{l}-0.038 \\
(-13.1)\end{array}$ & $\begin{array}{c}0.00 \\
(0.2)\end{array}$ & $\begin{array}{c}-0.01 \\
(-0.6) \\
{[0.02]}\end{array}$ & 0.94 \\
\hline
\end{tabular}

Source: See table 1.

a. Numbers in parentheses are $t$-statistics associated with the null hypothesis that the coefficients or the sum of coefficients is zero. Numbers in brackets show the significance level of the test that the set of coeficients is equal to zero. The second moments are Newey-West corrected.

b. The dividend yield and the real capital gain rate are lagged once. Inflation is entered with three lags; the number reported for inflation is the sum of the coefficients.

the first term in equation 3, and to a higher expected rate of growth of dividends, the second term in that equation. ${ }^{19}$

The expected rate of return on stocks implied by those regressions is plotted in figure 9, which plots both $E(D / P)$ and $E R_{s} \equiv E(D / P)+E A g_{d}$. The dividend yield shows a steady decrease since the early 1950 s, with a bulge in the late 1970s and early 1980s. It is now back at its level of the early 1970s. Because $E A g_{d}$ is estimated to be positively related to $D / P$, the implied real rate of return on stocks moves with the dividend yield, but with larger amplitude. It also shows a steady decline since 1950, with a bulge in the mid-1970s and early 1980s.

\section{The Evolution of the Equity Premium since 1927}

Having constructed series for $E R^{5}, E R^{20}$, and $E R_{s}$, I can now look at the equity premiums, defined either as $E X^{5} \equiv E R_{s}-E R^{5}$ or $E X^{20} \equiv$

19. This finding is related to the findings that the dividend yield predicts higher $n$-period rates of return on stocks, a relation to which I return in the next section. 
Figure 9. Expected Dividend Yield and Rate of Return on Stocks, 1929-93

Percent

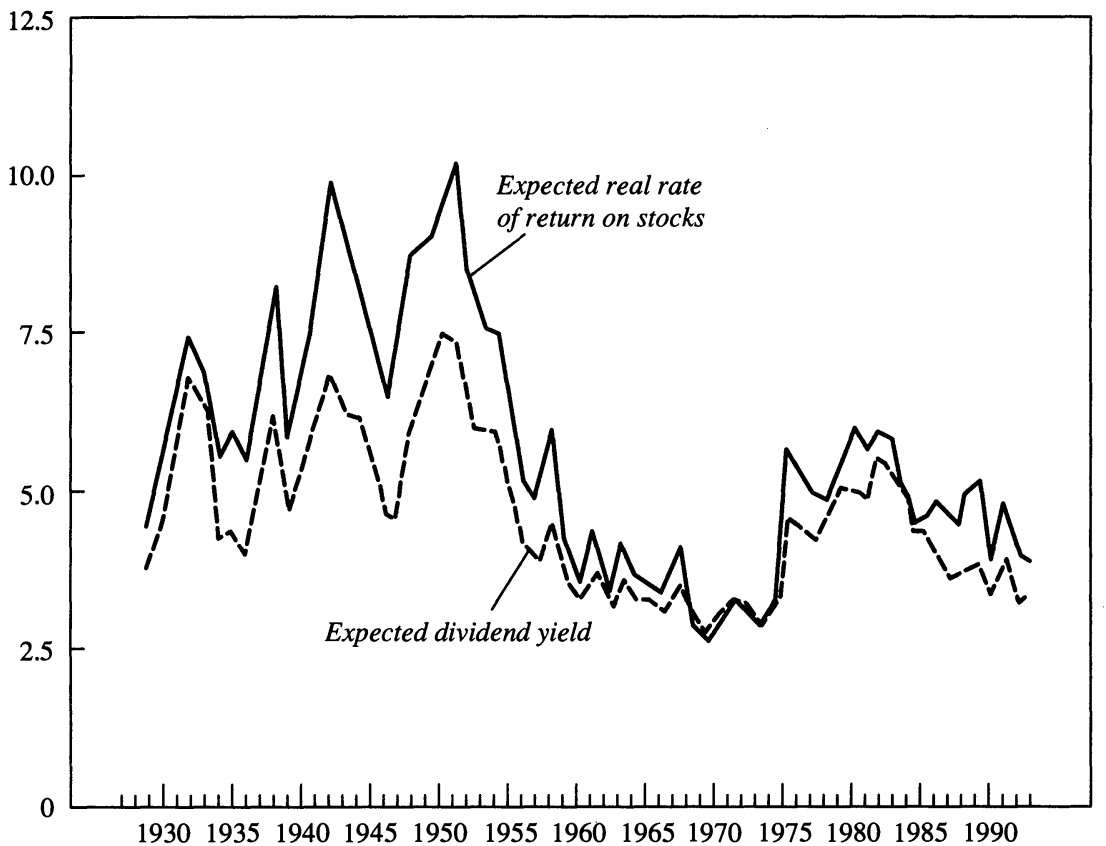

Source: Author's calculations based on first and third regressions in table 3 .

$E R_{s}-E R^{20}$. While the second definition is better in the sense of having closer durations of bonds and stocks, I also look at the first because I am more confident of the expected inflation measures over five years than over twenty years.

Figure 10 plots the two expected real rates on bonds, $E R^{5}, E R^{20}$, and the expected real rate on stocks, $E R_{s}$. What is most striking in the figure is how different the movements of expected rates of return on bonds and stocks have been over the last sixty-five years. Indeed, the main impression is one of expected returns moving in opposite directions. From the mid-1930s to the mid-1950s, expected rates of return on stocks were high while expected rates of return on medium-term or long-term bonds were low and often negative. The same is again true in the 1970s, although to a lesser extent. In contrast, the 1960 s, and even more so, the 1980 s, are characterized by relatively high expected bond rates and low expected stock rates of return. 
Figure 10. Expected Real Rates of Return for Stocks, Five-Year Bonds, and Twenty-Year Bonds, 1929-93

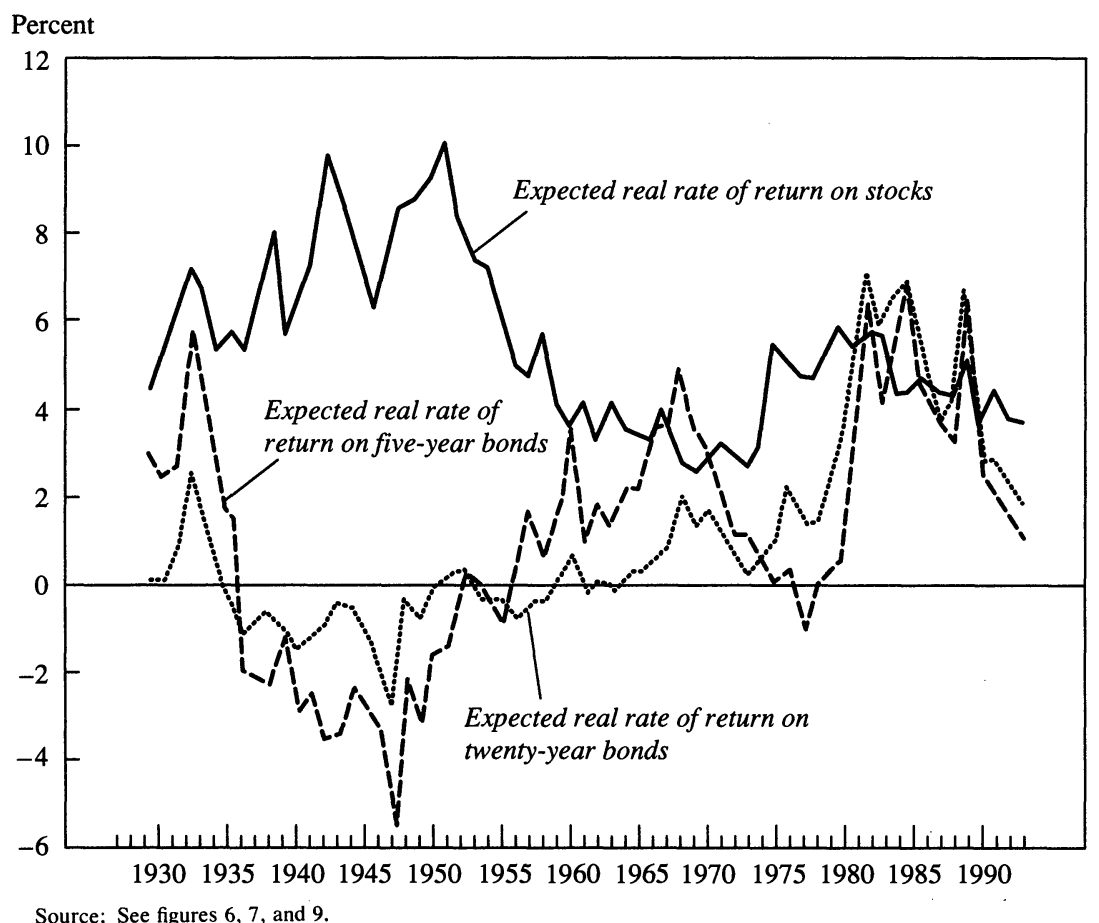

Figure 11 plots the two premiums: $E X^{5}$ and $E X^{20}$. The rest of the paper will focus on their evolution. But before that, as a check of robustness, I present an alternative construction.

\section{Realized Excess Returns and the Equity Premium}

An alternative to the construction of the equity premium used so far is to compute the realized excess rate of return on stocks over bonds over some holding period, project it on information available as of the beginning of the holding period, and look at the evolution of that projection over time. This is what I now do.

I define the realized equity premium from holding stocks over bonds over twenty years as

$$
R_{s}^{20}(t)-R_{T B}^{20}(t)
$$


Figure 11. Equity Premiums, 1929-93

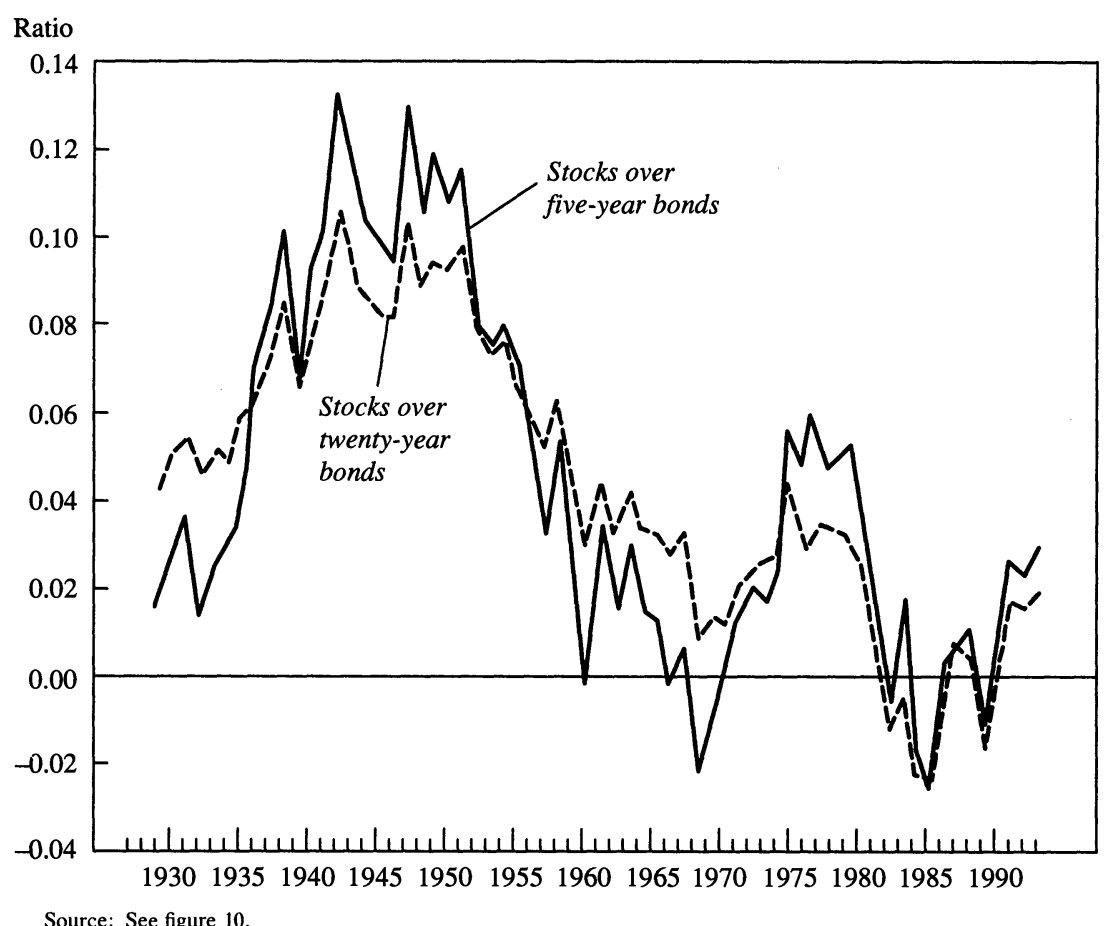

where

$$
R_{s}^{20}(t) \equiv \prod_{i=0}^{19}\left[1+R_{s}^{1}(t+i)\right]^{1 / 20}-1
$$

and

$$
R_{T B}^{20}(t) \equiv \prod_{i=0}^{19}\left[1+R_{T B}^{1}(t+i)\right]^{1 / 20}-1
$$

Note that the realized return on stocks includes actual dividends and capital gains that occur over the holding period. The realized rate of return from holding three-month T-bills over year $t$ is $R_{T B}(t)$. I compute the realized return on bonds from a strategy of rolling $T$-bills, rather than holding a twenty-year bond. I do this for comparability with other studies in finance, which have traditionally considered that strategy. 
Table 4. Regressions of Equity Premiums ${ }^{\mathrm{a}}$

\begin{tabular}{|c|c|c|c|c|c|c|}
\hline \multirow[b]{2}{*}{$\begin{array}{c}\text { Dependent } \\
\text { variable }\end{array}$} & \multirow[b]{2}{*}{ Period } & \multicolumn{4}{|c|}{ Independent variable ${ }^{\mathrm{b}}$} & \multirow[b]{2}{*}{$\bar{R}^{2}$} \\
\hline & & $\begin{array}{l}\text { Dividend } \\
\text { yield }\end{array}$ & $\begin{array}{l}\text { Real } \\
\text { capital } \\
\text { gain } \\
\text { rate }\end{array}$ & $\begin{array}{l}\text { Nominal } \\
\text { twenty- } \\
\text { year } \\
\text { yield }\end{array}$ & $\begin{array}{l}\text { Inflation } \\
\text { rate }\end{array}$ & \\
\hline \multirow[t]{2}{*}{$\begin{array}{l}\text { Alternative } \\
\text { realized } \\
\text { premium }^{c}\end{array}$} & $1929-73$ & $\begin{array}{r}1.31 \\
(1.8)\end{array}$ & $\begin{array}{l}-0.06 \\
(-3.4)\end{array}$ & $\begin{array}{l}-1.44 \\
(-2.1)\end{array}$ & $\begin{array}{l}0.11 \\
(0.8) \\
{[0.20]}\end{array}$ & 0.59 \\
\hline & $1954-73$ & $\begin{array}{c}0.92 \\
(5.0)\end{array}$ & $\begin{array}{l}-0.03 \\
(-3.1)\end{array}$ & $\begin{array}{l}-0.74 \\
(-3.5)\end{array}$ & $\begin{array}{l}0.90 \\
(5.6) \\
{[0.00]}\end{array}$ & 0.49 \\
\hline \multirow[t]{2}{*}{$\begin{array}{l}\text { Measure } \\
\text { from tables } \\
1-3^{d}\end{array}$} & $1929-73$ & $\begin{array}{r}0.83 \\
(2.3)\end{array}$ & $\begin{array}{l}-0.03 \\
(-3.1)\end{array}$ & $\begin{array}{l}-0.83 \\
(-2.5)\end{array}$ & $\begin{array}{l}0.27 \\
(2.5) \\
{[0.00]}\end{array}$ & 0.52 \\
\hline & $1954-73$ & $\begin{array}{r}0.47 \\
(2.1)\end{array}$ & $\begin{array}{l}-0.03 \\
(-3.5)\end{array}$ & $\begin{array}{l}-0.41 \\
(-2.3)\end{array}$ & $\begin{array}{l}0.10 \\
(0.7) \\
{[0.00]}\end{array}$ & 0.76 \\
\hline
\end{tabular}

Source: See table 1.

a. The period of estimation ends in 1973 for the first two regressions, as this is the last year when the realized premium can be computed. For comparison's sake, the same periods are used for the other two regressions. Numbers in parentheses are $t$-statistics associated with the null hypothesis that the coefficient, or sum of coefficients, is zero. Numbers in brackets show the significance level of the test that the set of coefficients is equal to zero. The second moments are Newey-West corrected.

b. The dividend yield and the real capital gain rate are lagged once. Inflation is entered with three lags; the number reported for inflation is the sum of the coefficients.

c. Defined as $R_{s}^{20}(t)-R^{20}(t)$, the realized rate of return on holding stocks for twenty years minus the realized rate of return from rolling treasury bills for twenty years.

d. Defined as $\left[D / P(t)+A g_{d}(t)\right]-\left[I^{20}(t)-A \pi^{20}(t)\right]$. See the text for further details.

Having constructed the realized premium for 1927-73 (because the realized twenty-year premium from 1973 to 1992 is the last one available), I then regress it on the same four variables as before, using fortyyear rolling regressions. I use rolling regressions for samples starting in 1929 to samples starting in 1954 , so that the last regression uses only twenty observations.

A summary of those regressions is given in the top half of table 4, for both the whole sample-which again is never used to construct the expected premium but summarizes the data-and for the last rolling sample, 1954-73. For comparison, the bottom half of the table gives the results of regressions using the ex post value of $X^{20}$ constructed earlier as the dependent variable, over the same time periods. Except for differences in sample periods, these last two regressions are just summaries 
of the regressions of the different components presented in the earlier three tables. ${ }^{20}$

The striking feature of the two regressions using realized returns in the top half of table 4, which has been documented and discussed at length elsewhere, is the strong positive effect of the dividend yield on the equity premium..$^{21}$ The other, nearly equally striking, aspect of the two regressions is the strong negative effect of the long nominal rate. ${ }^{22}$ The two sets of regressions, using the two alternative equity premiums, show rather similar coefficients. One relevant difference is the effect of past inflation on the two premiums for the sample 1954-73, with a much stronger effect on the first than on the second. However, the interpretation of this finding is not obvious, given the presence of the other variables; I return to that issue in a later section.

The important question here is whether the two estimated premiums move together. Using the 1929-73 regressions, the predicted values from the rolling regressions are plotted in figure 12 through 1993. The top frame reproduces the evolution of the premium (using twenty-year bonds) given in figure 11 and the bottom frame gives the evolution of my alternative measure, the projection of twenty-year holding-period excess realized return. Each of the two panels also gives the one standard deviation band associated with the point estimates of the equity premium at each point in time (where the standard deviations underlying the band are computed taking into account the moving average structure of the residuals in the equation). The conclusions are simple. The two constructed series move very much in the same way. The standard deviation bands vary from 3 to 6 percent. While large, they still show clear evolutions, to which I now turn.

\section{Trends and Inflation}

I draw two main conclusions from the evolutions of the various constructed premiums in figures 11 and 12 . First, the premiums display clear

20. The realized value of the premium, $X^{20}$, is defined as $(D / P)+A g_{d}-I^{20}+A \pi^{20}$. Tables 2 and 3 give the regressions of $A \pi^{20}, D / P$, and $A g_{d}$ on the four variables. Given that $I^{20}$ is one of these four variables, the regression of $P^{20}$ on those variables is $P^{0}$ itself.

21. See, for example, Fama and French (1988) and Cutler, Poterba, and Summers (1990).

22. I have not explored the effects of allowing for rates of different maturities as independent variables. Campbell (1987) shows that yield spreads between bonds of different maturities help predict monthly returns on stocks in excess of the one-month rate. 
Figure 12. Equity Premiums, 1929-93
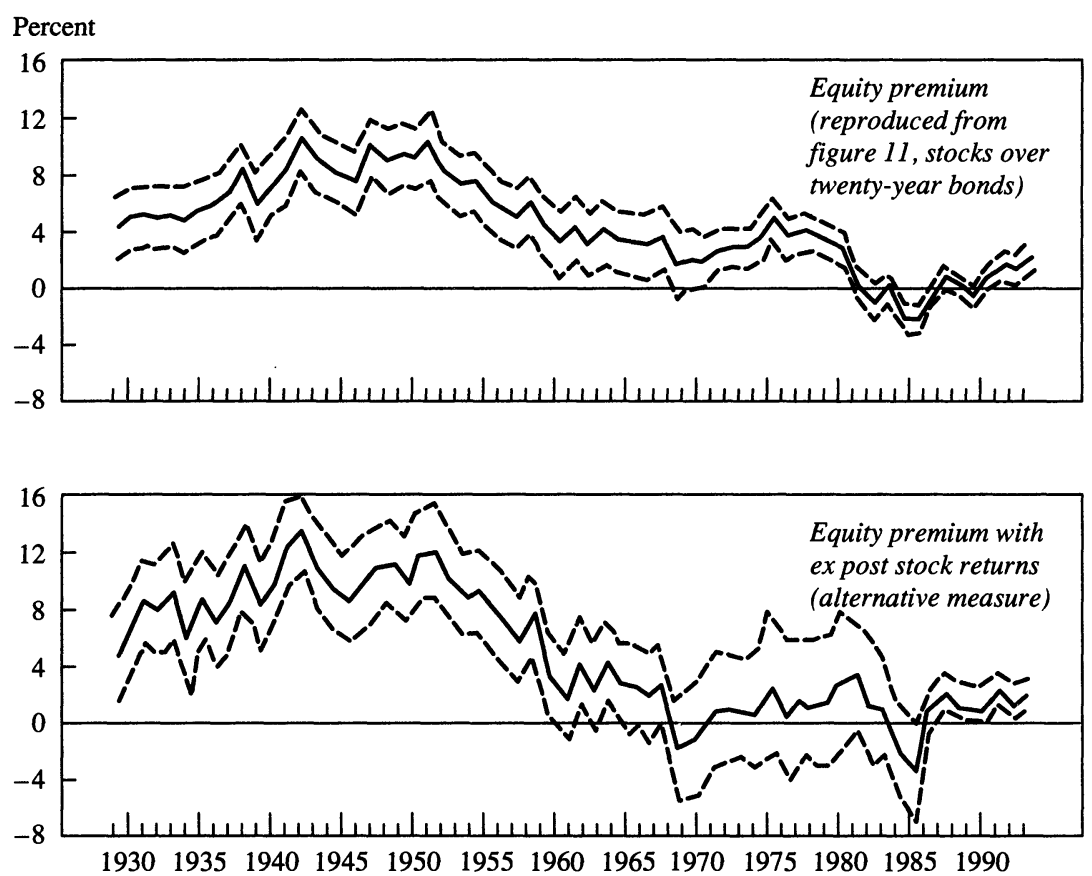

Source: Stock returns are predicted values from regressions shown in table 4, and bond returns are described in the text.

a. Dashed lines indicate one standard deviation band.

low-frequency movements, a steady increase from the early 1930s to the mid-1940s, and a trend decline since the early 1950s. The premiums rise from 3 to 5 percent in the early 1930s, peak at more than 10 percent in the late 1940s, and drop to 2 or 3 percent today. Current values of the premiums thus appear to be roughly on trend. This can be put in the longer historical perspective with the data set provided by Jeremy Siegel, who constructs and examines a series for the equity premium since $1800 .{ }^{23}$ Rather than attempting to construct a series for the expected premium as I have done here, Siegel uses a thirty-year centered moving average of the ex post premium as an estimate of the ex ante premium. After 1927, his constructed premium has the same general evolution as the one plotted in figure 11. Before 1927, the premium is close to

23. Siegel (1992b). 
zero from 1800 to 1850 , a period of high real rates on bonds. It is rather stable from 1850 to the early 1930 s, with a mean of about 4 percent. Thus, as Siegel emphasizes, the period from the early 1930s to the late 1940s appears anomalous.

Second, the premiums in the figures display higher-frequency movements; these appear to be correlated with movements in inflation. The postwar decline in the premium was temporarily reversed in the 1970s, a period of sharply higher inflation. This increase, in turn, was reversed in the 1980s, with a return to trend or decline below it, when inflation was sharply lower. ${ }^{24}$ The bulge of the 1970 s is substantially smaller for the twenty-year premium than for the five-year premium. But the evolutions of the two premiums are otherwise rather similar.

How close are movements in the premium and in inflation? A first rough pass at the answer is given in figure 13, which plots deviations of the five-year and twenty-year premiums and of inflation from ten-year past moving averages of themselves, a flexible way of removing low- frequency components in the series. The relation clearly exists. The corresponding regressions give

$$
\begin{gathered}
\widehat{E X^{5}}(t)=-0.0045+0.40 \hat{\pi}(t-1), \\
(4.5) \\
\overline{\mathrm{R}}^{2}=0.26 ; \text { Durbin-Watson }=0.55 ; \text { period: } 1932-88 ; \\
(t \text {-statistic in parentheses })
\end{gathered}
$$

and

$$
\begin{gathered}
\widehat{E X^{20}}(t)=-0.016+0.18 \hat{\pi}(t-1), \\
(2.8) \\
\overline{\mathrm{R}}^{2}=0.11 ; \text { Durbin-Watson }=0.35 ; \text { period: } 1932-88 ; \\
(t \text {-statistic in parentheses })
\end{gathered}
$$

where $\widehat{E X^{5}}(t) \equiv E X^{5}(t)-0.1 \sum_{i=0}^{9} E X^{5}(t-i)$ and similarly for $\widehat{E X}^{20}(t)$ and $\hat{\pi}(t)$. The inflation series is lagged once, as $\pi(t-1)$ is the most recent inflation rate in the information set at time $t$. When the regressions are estimated with an AR(1) correction, the coefficients on inflation are smaller: 0.19 and 0.11 , respectively. ${ }^{25}$ These results suggest that a decline in in-

24. A similar set of observations is made by Summers (1983).

25. These regressions are merely data descriptions. The series that are used are fitted values from rolling regressions, minus a moving average of themselves, and thus display strange time-series characteristics. 
Figure 13. Deviations from the Ten-Year Moving Averages of the Five-Year and Twenty-Year Equity Premiums and Inflation, 1935-93

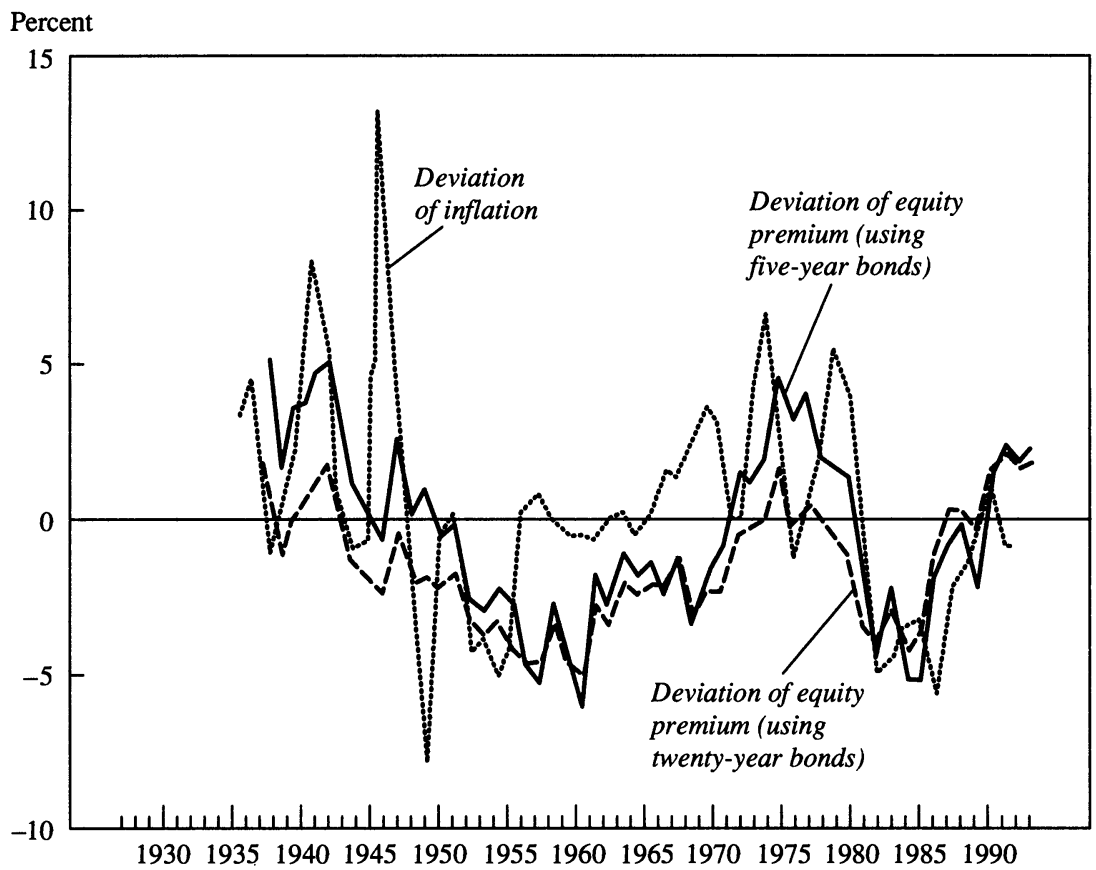

Source: Author's calculations based on figures 5 and 11

a. Series are plotted as deviations from ten-year moving averages to remove low-frequency components of the series.

flation of 1 percent decreases the equity premium initially by between 0.1 and 0.4 percent. The effect largely disappears over time (after ten years, for the particular specification used here). The next two sections look at both characteristics, the trend and the relation to inflation, in more detail.

\section{Trend Movements and the Premium}

In explaining low-frequency movements in the premium, econometrics cannot be of much use. Instead, one must look for variables that have the same general time shape as the premium and may plausibly have affected it. 
This approach nevertheless allows one to rule out a number of potential factors, or at least to rule them out as major explanatory variables. One such factor is government debt. To the extent that government debt is perceived as net wealth, an increase in its relative supply should lead to an increase in its relative rate of return, and thus to a lower equity premium. Thus, if the evolution of government debt had been one of the main determinants of the premium, they should have moved in opposite directions in the sample. The data are very much at odds with this implication. The 1940s are associated both with a large buildup of debt and a high premium. Until the 1970 s, the decline in the premium from the 1950s on coincides with a steady decline in the debt-GDP ratio. Only in the 1980 s does the relation appear to go the right way. This general impression is confirmed by an econometric study by Paolo Mauro based on panel data from twenty countries since 1960 , which finds a positive association between debt-GDP ratios and the equity premium. ${ }^{26}$ This route does not appear promising.

Another potential cause is a change in the relative riskiness of stocks and bonds. Many studies have focused on the evolution of various measures of riskiness. The evidence is summarized in figure 14, which plots the rolling variance of quarterly stock returns and the rolling covariance of quarterly twenty-year bond and stock returns since 1928, with each of the two moments estimated over twelve quarters. There is little evidence of trends in either. The striking feature is the volatility of stock returns in the late 1920 s and early 1930 s. This fact suggests, however, a potential explanation: that the unusually high equity premium of the late 1930s and 1940s was in part caused by the perception of high volatility from the movements in the stock market in the late 1920s and early 1930 s. ${ }^{27}$ Such a perception, the explanation goes, led many investors not to invest in stocks at any price, but to shift instead to government securities, generating a high equity premium. ${ }^{28}$

One of the strengths of this explanation is that it also explains why the equity premium went steadily down from the early 1950 s on. As memo-

26. Mauro (1992).

27. This argument is made by Siegel (1992b).

28. Patriotism, and the fact that previous wars had been followed by deflation, may also explain why people were willing to hold bonds during World War II at what I have estimated, with the benefit of hindsight, to be negative expected real rates. But these factors do not explain why the premium remained high for many years after the wal, and after the 1947 inflation. 
Figure 14. Rolling Variance of Stock Returns and Covariance of Stock and Bond Returns, 1928-93

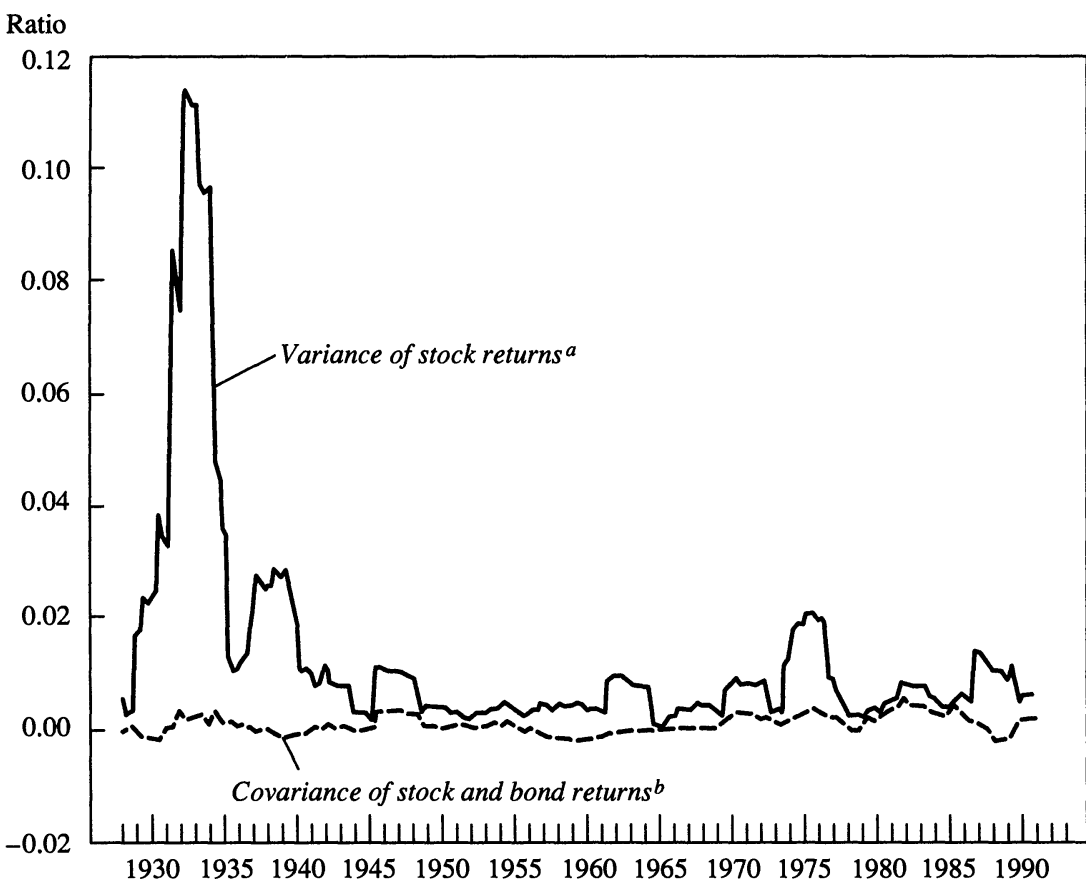

Source: Author's calculations based on Ibbotson (1992)

a. Calculated as the rolling twelve-quarter variance of realized rates of return on stocks.

b. Calculated as the rolling twelve-quarter covariance of realized rates of return on stocks and bonds.

ries of the 1930s faded, people slowly returned to stocks, discovering what Rajnish Mehra and Edward C. Prescott later established: namely, that at equity premiums prevailing after World War II, holding stocks was very appealing. ${ }^{29}$ The point is often made along the following lines: since 1927, the realized return from holding stocks has exceeded that of holding bonds over every single twenty-year period.$^{30}$ Also, institutional investors have become increasingly important. Given their mandate,

29. Mehra and Prescott (1985).

30. Computations along those lines are given in MaCurdy and Shoven (1992). They should be given with the warning that they may be less impressive than they look. Overlapping twenty-year realized rates of return over the sample are not independent observations. 
one would expect managers of pension funds to think in terms of longer horizons and to act to take advantage of an attractive equity premium. ${ }^{31}$ In the United States, the share of equities held by pension funds (state and local, and private) has gone from about 1 percent in 1950, to 9 percent in 1970, to 29 percent today. In the United Kingdom, the share has gone from 6 percent in 1963 to more than 30 percent today. These evolutions appear to be the most promising lead to explain the lowfrequency movements in the premium.

\section{Inflation and the Premium}

If identifying the causes of the low-frequency movements in the premium is difficult, identifying the reasons why inflation affects the premium is even more so. A large body of research has explored various mechanisms through which inflation may affect the premium, either through the interaction between inflation and taxation, inflation and risk, or inflation and money illusion. ${ }^{32}$ In this section, I will limit my ambitions to improving on the rough estimates of the observed relation between inflation and the premium given earlier. I shall also relate the results to the equally large body of empirical research on the relation of inflation to bond and stock returns.

In the regressions of the components of the equity premium summarized in tables 1 to 3 , one of the variables was lagged inflation. But the coefficients on inflation were difficult to interpret because they presented only the effects of inflation given the other variables in the regression. The methodology, however, is easily extended to yield both the direct and the indirect effects of inflation. The idea is to estimate the joint

31. In the theory of behavior under uncertainty based on loss aversion and mental accounts developed by Kahneman and Tversky (1979) and applied by Benartzi and Thaler (1993) to the equity premium, there is a strong relation between the horizon over which investors assess the results of their portfolio and the equilibrium equity premium. In figure 3 of Benartzi and Thaler (1993), premiums of 6 percent correspond to horizons of less than one year, while premiums of 2 to 3 percent correspond to horizons of five to ten years.

32. That investors may be comparing nominal rates on bonds to dividend yields for stocks was argued by Modigliani and Cohn (1979), who predicted that if inflation came down, the equity premium would also decrease. As is clear from the previous figures, their prediction held very well in the 1980 s. 
process for the four variables included in the earlier equations, and then use this, as well as the auxiliary equations for the annuity values I estimated earlier, to trace the effects of an innovation in inflation on the components of the premium.

I implement this as follows. Rather than working with the four-variable vector autoregression (VAR) in the dividend yield, the rate of real capital gain on stocks, the nominal bond rate, and inflation, I use two separate VARs: one for nominal rates and inflation, and one for dividend yields, the rate of capital gain, and inflation. I do this to deal with subsample instability; I prefer to use rolling samples to capture the change in the joint processes through time, and using VARs with fewer variables conserves on degrees of freedom.

Using the first VAR and an auxiliary equation for the annuity value of inflation, I trace the effects of an innovation in inflation on nominal and expected real bond rates. Using the second and an auxiliary equation for the annuity value of dividend growth, I trace the effects of an innovation in inflation on the expected rate of return on stocks. Putting the results together gives the effects of an innovation in inflation on the premium. ${ }^{33}$

\section{Real Bond Rates and Inflation}

To trace the effects of inflation on either five-year or twenty-year real bond rates, I estimate for each one the following bivariate system,

$$
\begin{array}{rlrl}
I^{n}(t+1) & =a_{11} \pi(t)+a_{11}(L) \pi(t-1)+a_{12} I^{n}(t)+\epsilon_{I} n(t) \\
\pi(t) & = & a_{21}(L) \pi(t-1)+a_{22} I^{n}(t)+\epsilon_{\pi}(t),
\end{array}
$$

and the auxiliary regression,

$$
A \pi^{n}(t)=a_{01}(L) \pi(t-1) \quad+a_{02} I^{n}(t)+\epsilon_{A}(t),
$$

33. The approach followed in this section is closely related to that taken by Campbell and Ammer (1992) and by Shiller and Beltratti (1992). Both those papers also use a VAR approach, with a similar list of variables, to characterize the joint movement of stock and bond returns. They differ from this section in both minor and less minor ways. Minor ways include the use of log-linear rather than linear approximations, postwar monthly data (in Campbell and Ammer), a slightly different list of variables, and different assumptions about the potential presence of unit roots. In contrast to my paper, Shiller and Beltratti focus on tests of hypotheses, including that of a constant equity premium. Campbell and Ammer focus on explaining realized stock and bond returns as a function of news about future dividends, inflation, real bond rates, and the equity premium. 
where $a_{11}(L), a_{21}(L)$, and $a_{01}(L)$ are lag polynomials of order 3 , and $a_{11}$, $a_{12}, a_{22}$, and $a_{02}$ are scalars. The choice of the order of lags is, as before, determined by considerations of degrees of freedom; the results below are also robust to the presence of longer lags on $I^{n}$.

The slight awkwardness of notation, with the two dependent variables being $I^{n}(t+1)$ and $\pi(t)$, comes from the timing conventions. The yield to maturity at the beginning of year $t+1$, or equivalently at the end of year $t$, is $I^{n}(t+1)$. Inflation during year $t$ is $\pi(t)$.

I estimate the VAR, and the auxiliary equation for expected inflation, on rolling samples of forty years, from 1929-68 to 1953-92. For the estimated system associated with each subsample, I then trace the effects of a 1 percent innovation in $\epsilon_{\pi}$ in year 0 on $I^{n}(t), \pi(t)$ and $E A \pi^{n}(t)$, in years 0 to $m$. In year 0 , the innovation in inflation affects only inflation, as both the nominal rate and the expected annuity value of inflation are measured as of the beginning of the year. From year 1 on, nominal rates, inflation, and expected inflation are all affected by the shock to inflation in year 0 .

The purpose of computing these impulse responses is to capture the dynamic effects of a shock to inflation at time $t$ on future expected inflation and expected real rates. The limitations of the exercise come from the nature of VARs and impulse responses; it is worth making them explicit.

The first is the implicit identification condition in the VAR, which takes the form of the presence of $\pi(t)$ in the first equation, but not of $I^{n}(t$ $+1)$ in the second equation. The assumption implicit in that specification is that the correlation between innovations in inflation in year $t$ and innovations in the nominal rate from the beginning of year $t$ to the beginning of year $t+1$ reflects the effects of unexpected inflation on nominal rates, not the reverse.

The second limitation comes from the specification of the VAR in only two variables, nominal rates and inflation. Thus, the dynamic effects captured in the impulse responses below reflect not only the effects of inflation per se, but also of all the variables that move with inflation and are not included in the regression.

The third limitation is that nominal rates may be in part "information variables," variables embodying information about future inflation not contained in current and past inflation. Thus, some of the changes in inflation will appear as innovations in yields rather than in inflation. Thus, 
Table 5. Dynamic Effects of a 1 Percentage Point Innovation in Inflation on the Real Rate of Return on Five-year Bonds ${ }^{a}$

Percentage points

\begin{tabular}{cccccc}
\hline Sample & Period & Inflation & $\begin{array}{c}\text { Nominal } \\
\text { five-year } \\
\text { yield }\end{array}$ & $\begin{array}{c}\text { Expected } \\
\text { inflation } \\
\text { (five-year) }\end{array}$ & $\begin{array}{c}\text { Expected } \\
\text { real } \\
\text { return }^{\mathrm{c}}\end{array}$ \\
\hline $1929-68$ & 0 & 1.00 & 0.00 & 0.00 & 0.00 \\
& 1 & $0.56^{\mathrm{e}}$ & 0.01 & $0.19^{\mathrm{d}}$ & $-0.17^{\mathrm{d}}$ \\
& 2 & 0.10 & 0.02 & 0.05 & -0.04 \\
$1939-78$ & 3 & -0.10 & 0.04 & 0.09 & -0.05 \\
& 0 & 1.00 & 0.00 & 0.00 & 0.00 \\
$1949-88$ & 1 & $0.54^{\mathrm{e}}$ & 0.03 & $0.25^{\mathrm{e}}$ & $-0.22^{\mathrm{e}}$ \\
& 2 & 0.00 & $0.05^{\mathrm{d}}$ & $0.13^{\mathrm{d}}$ & -0.08 \\
& 3 & -0.11 & 0.04 & $0.20^{\mathrm{d}}$ & $-0.16^{\mathrm{d}}$ \\
& 0 & 1.00 & 0.00 & 0.00 & 0.00 \\
$1953-92$ & 1 & $0.90^{\mathrm{e}}$ & $0.24^{\mathrm{e}}$ & $0.43^{\mathrm{e}}$ & $-0.18^{\mathrm{d}}$ \\
& 2 & $0.36^{\mathrm{e}}$ & $0.35^{\mathrm{e}}$ & $0.33^{\mathrm{e}}$ & 0.02 \\
& 3 & 0.11 & $0.35^{\mathrm{e}}$ & $0.23^{\mathrm{d}}$ & 0.11 \\
& 0 & 1.00 & 0.00 & 0.00 & 0.00 \\
& 1 & $1.06^{\mathrm{e}}$ & $0.31^{\mathrm{e}}$ & $0.59^{\mathrm{e}}$ & $-0.27^{\mathrm{d}}$ \\
& 2 & $0.59^{\mathrm{e}}$ & $0.44^{\mathrm{e}}$ & $0.36^{\mathrm{e}}$ & 0.08 \\
& 3 & $0.32^{\mathrm{d}}$ & $0.40^{\mathrm{e}}$ & $0.38^{\mathrm{e}}$ & 0.03 \\
\hline
\end{tabular}

Source: See table 1 .

a. The responses are obtained by simulation of a dynamic system, estimated in each case over the sample period indicated in the first column, in $\left(I^{5}, \pi\right)$ and an auxiliary equation for $A \pi^{5}$. The numbers are responses to an unexpected movement in inflation of 1 percentage point in period 0.

b. Expected inflation, $E A \pi^{5}$, is for a five-year horizon.

c. Expected real rate of return on five-year bonds, defined as $E R^{5}$ in the text.

d. $t$-statistic between 1 and 2 .

e. $t$-statistic greater than 2 .

the impulse responses below capture only the dynamic effects of those innovations in inflation that were not anticipated by the bond market.

The results of the dynamic effects of an inflation innovation on fiveyear and twenty-year nominal and real bond rates are summarized in tables 5 and 6 . A different set of impulse responses is associated with each rolling regression. The tables present impulse responses for rolling samples ten years apart: 1929-68, 1939-78, 1949-88, and the latest sample available, 1953-92.

Together, the two tables give a picture in which expected inflation has an effect of real rates, but an effect that disappears after a couple of years. The effects of a 1 percentage point innovation in inflation during year 0 typically leads to a decline in five-year real rates of about 0.2 percent at the beginning of year 1 . The effect is largely gone in year 2 . The effects of a similar innovation leads to a decline in twenty-year real rates 
Table 6. Dynamic Effects of a 1 Percentage Point Innovation in Inflation on the Real Rate of Return on Twenty-year Bonds ${ }^{\mathrm{a}}$

Percentage Points

\begin{tabular}{cccccc}
\hline Sample & Period & Inflation & $\begin{array}{c}\text { Nominal } \\
\text { twenty- } \\
\text { year yield }\end{array}$ & $\begin{array}{c}\text { Expected } \\
\text { inflation }^{\mathrm{b}} \\
\text { (twenty- } \\
\text { year) }\end{array}$ & $\begin{array}{c}\text { Expected } \\
\text { real } \\
\text { return }\end{array}$ \\
\hline $1929-68$ & 0 & 1.00 & 0.00 & 0.00 & 0.00 \\
& 1 & $0.55^{\mathrm{e}}$ & $0.02^{\mathrm{d}}$ & $0.12^{\mathrm{d}}$ & $-0.10^{\mathrm{d}}$ \\
& 2 & 0.07 & $0.04^{\mathrm{d}}$ & 0.05 & -0.01 \\
$1939-78$ & 3 & -0.14 & $0.06^{\mathrm{d}}$ & 0.06 & -0.01 \\
& 0 & 1.00 & 0.00 & 0.00 & 0.00 \\
& 1 & $0.52^{\mathrm{e}}$ & $0.03^{\mathrm{d}}$ & 0.03 & 0.00 \\
$1949-88$ & 2 & 0.02 & $0.06^{\mathrm{d}}$ & -0.02 & $0.08^{\mathrm{d}}$ \\
& 3 & -0.14 & 0.03 & -0.03 & $0.06^{\mathrm{d}}$ \\
& 0 & 1.00 & 0.00 & 0.00 & 0.00 \\
$1953-92$ & 1 & $0.90^{\mathrm{e}}$ & $0.19^{\mathrm{e}}$ & $0.20^{\mathrm{d}}$ & -0.01 \\
& 2 & $0.35^{\mathrm{d}}$ & $0.29^{\mathrm{e}}$ & $0.17^{\mathrm{d}}$ & $0.12^{\mathrm{d}}$ \\
& 3 & 0.09 & $0.32^{\mathrm{e}}$ & 0.02 & $0.30^{\mathrm{e}}$ \\
& 0 & 1.00 & 0.00 & 0.00 & 0.00 \\
& 1 & $1.06^{\mathrm{e}}$ & $0.24^{\mathrm{e}}$ & $0.33^{\mathrm{e}}$ & -0.08 \\
& 2 & $0.60^{\mathrm{e}}$ & $0.37^{\mathrm{e}}$ & $0.18^{\mathrm{d}}$ & $0.19^{\mathrm{e}}$ \\
& 3 & $0.32^{\mathrm{d}}$ & $0.38^{\mathrm{e}}$ & 0.11 & $0.26^{\mathrm{e}}$ \\
\hline
\end{tabular}

Source: See table 1 .

a. The responses are obtained by simulation of a dynamic system, estimated in each case over the sample period indicated in the first column, in $\left(I^{20}, \pi\right)$ and an auxiliary equation for $A \pi^{20}$. The numbers are responses to an unexpected movement in inflation of 1 percentage point in period 0 .

b. Expected inflation, $E A \pi^{20}$, is for a twenty-year horizon.

c. Expected real rate of return on twenty-year bonds, defined as $E R^{20}$ in the text.

d. $t$-statistic between 1 and 2 .

e. $t$-statistic greater than 2 .

of about 0.1 percent at the beginning of year 1 . Again the effect is largely gone in year 2 . Thus, the Fisher effect seems to hold after only a couple of years. ${ }^{34}$

I expected the effect of inflation on real rates to be stronger. The proximate source of the weak effect can be understood from the tables. For most of the sample, an innovation to inflation has only a transitory effect on inflation. For the first two rolling samples, the effect of an innovation on inflation is gone after two years. Only in the postwar sample does inflation show substantial persistence. ${ }^{35}$ Thus, while nominal rates do not

34. This result is robust to a more generous specification of the lag structure.

35. This fact casts doubt on the research using cointegration methods to study the Fisher effect. McCallum (1984) makes a similar point. For most of the period under study, inflation is clearly a stationary process. Moreover, the more recent period-when a unit root cannot be rejected-is too short for cointegration methods to be reliable. 
respond very much to innovations in inflation, neither do the expected values of inflation over the life of the five-year and especially the twentyyear bonds. Thus, real rates do not move very much in response to an inflation shock.

Independent-and I think better-evidence can again be obtained for the recent past from the indexed bond market in the United Kingdom. In combination with the market for nominal bonds and the assumption of arbitrage, it can be used to get direct measures of inflation and study their relation to real rates. This has been done by Woodward using monthly data since $1982 .{ }^{36}$ His results are surprisingly similar to those presented above. While he finds an effect of expected inflation on real rates for maturities up to ten years (with an effect of about -0.3 percent on real rates for a 1.0 percentage point increase in expected inflation for maturities around five years), the data are consistent with a one-for-one effect of expected inflation on nominal rates for maturities longer than ten years.

\section{Rates of Return on Stocks and Inflation}

To trace the effects of inflation on rates of return on stocks, I estimate the following trivariate system,

$$
\begin{aligned}
(D / P)(t)= & b_{11} \pi(t)+b_{11}(L) \pi(t-1)+b_{12}(D / P)(t-1) \\
& +b_{13} g_{p}(t-1)+\epsilon_{D P}(t), \\
g_{p}(t)= & b_{21} \pi(t)+b_{22}(L) \pi(t-1)+b_{22}(D / P)(t-1) \\
& +b_{23} g_{p}(t-1)+\epsilon_{g p}(t), \\
\pi(t)= & \quad b_{31}(L) \pi(t-1)+b_{32}(D / P)(t-1) \\
& +b_{33} g_{p}(t-1)+\epsilon_{\pi}(t),
\end{aligned}
$$

and the auxiliary regression,

$$
\begin{aligned}
A g_{d}(t)= & b_{01}(L) \pi(t-1)+b_{02}(D / P)(t-1) \\
& +b_{03} g_{p}(t-1)+\epsilon_{A}(t),
\end{aligned}
$$

where the $b_{11}(L), b_{21}(L), b_{31}(L), b_{01}(L)$ are lag polynomials of order 3. I then proceed in the same way as for bonds, estimating rolling samples,

36. Woodward (1992). 
Table 7. Dynamic Effects of a 1 Percentage Point Innovation in Inflation on the Real Rate of Return on Stocks ${ }^{\mathrm{a}}$

Percentage points

\begin{tabular}{ccccccc}
\hline Sample & Period & Inflation & $\begin{array}{c}\text { Dividend } \\
\text { yield }\end{array}$ & $\begin{array}{c}\text { Expected } \\
\text { growth } \\
\text { rate of } \\
\text { future } \\
\text { dividends }\end{array}$ & $\begin{array}{c}\text { Real } \\
\text { capital } \\
\text { gain } \\
\text { rate }\end{array}$ & $\begin{array}{c}\text { Expected } \\
\text { real } \\
\text { return }\end{array}$ \\
\hline $1929-68$ & 0 & 1.00 & 0.01 & 0.00 & -0.48 & 0.00 \\
& 1 & $0.63^{\mathrm{e}}$ & -0.01 & $0.11^{\mathrm{e}}$ & $0.35^{\mathrm{d}}$ & 0.10 \\
& 2 & $0.21^{\mathrm{d}}$ & 0.00 & $0.08^{\mathrm{d}}$ & $0.02^{\mathrm{d}}$ & 0.09 \\
& 3 & 0.02 & 0.04 & 0.04 & $0.36^{\mathrm{d}}$ & 0.09 \\
$1939-78$ & 0 & 1.00 & 0.01 & 0.00 & $-3.01^{\mathrm{e}}$ & 0.00 \\
& 1 & $0.55^{\mathrm{e}}$ & $0.05^{\mathrm{d}}$ & 0.09 & -0.66 & $0.14^{\mathrm{e}}$ \\
& 2 & 0.01 & $0.06^{\mathrm{d}}$ & 0.12 & 0.55 & $0.19^{\mathrm{e}}$ \\
$1949-88$ & 3 & -0.10 & $0.10^{\mathrm{d}}$ & 0.06 & 0.61 & $0.16^{\mathrm{d}}$ \\
& 0 & 1.00 & $0.02^{\mathrm{d}}$ & 0.00 & $-2.66^{\mathrm{e}}$ & 0.00 \\
& 1 & $0.95^{\mathrm{e}}$ & $0.05^{\mathrm{d}}$ & -0.01 & $-1.70^{\mathrm{d}}$ & 0.03 \\
& 2 & $0.40^{\mathrm{d}}$ & 0.05 & 0.05 & 0.54 & $0.10^{\mathrm{d}}$ \\
$1953-92$ & 3 & 0.18 & $0.06^{\mathrm{d}}$ & 0.06 & -0.48 & $0.12^{\mathrm{d}}$ \\
& 0 & 1.00 & 0.00 & 0.00 & $-3.93^{\mathrm{e}}$ & 0.00 \\
& 1 & $1.04^{\mathrm{e}}$ & $0.14^{\mathrm{e}}$ & -0.02 & $-1.47^{\mathrm{d}}$ & $0.13^{\mathrm{d}}$ \\
& 2 & $0.55^{\mathrm{e}}$ & $0.14^{\mathrm{e}}$ & 0.06 & $1.49^{\mathrm{d}}$ & $0.21^{\mathrm{e}}$ \\
& 3 & $0.35^{\mathrm{d}}$ & $0.07^{\mathrm{d}}$ & 0.07 & 0.74 & $0.14^{\mathrm{d}}$ \\
\hline
\end{tabular}

Source: See table 1.

a. The responses are obtained by simulation of a dynamic system, estimated in each case over the sample period indicated in the first column, in $\left(D / P, g_{p}, \pi\right)$ and an auxiliary equation for $A g_{d}$. The numbers are responses to an unexpected movement in inflation of 1 percentage point in period 0 .

b. The expected value of the annuity value of the growth rate of future dividends, $E A g_{d}$.

c. Expected real rate of return on stocks, $E R_{s}$, constructed as $E(D / P)+E A g_{d}$.

d. $t$-statistic between 1 and 2 .

e. $t$-statistic greater than 2 .

and for each one, computing the dynamic effects of an innovation in inflation of 1 percent in year 0 on the dividend yield, the rate of capital gain, and the rate of return on stocks.

The same caveats apply to stocks as to bonds. The implicit assumption behind the presence of current inflation in the first two equations is that any correlation between inflation and unanticipated capital gains or movements in the dividend yield, and inflation is interpreted as reflecting the effects of inflation on the other variables. Again, some of the movements of inflation are likely to be anticipated by the stock market, and thus to be captured by innovations in the dividend yield or the rate of capital gain, rather than by innovations in the inflation equation.

The results are presented in table 7 . In year 0 , the numbers in the table give the effects of unexpected inflation. More precisely, they reflect the 
effects of unexpected inflation on the dividend yield and the rate of change of real stock prices within the year. ${ }^{37}$ In years 1 and higher, the numbers reflect the effects of anticipated inflation, namely the effects of the innovation at time 0 on the dividend yield, the rate of capital gain, and the rate of return on stocks, defined as the expected dividend yield over the year plus the expected annuity value of real dividend growth. I see three main results in that table.

The first is that an unexpected increase in inflation in year 0 leads to a sharp decrease in stock prices in that year. This has been widely documented elsewhere. The estimated effect has increased steadily through time, from a -0.48 percent decrease in real prices for a 1.0 percentage point increase in inflation in the first subsample, to a -3.93 percent decrease in real prices in the latest subsample. Other things being equal, this leads in later years to a higher expected dividend yield in year 1 in response to an innovation in inflation in year 0 .

The second result is the positive effect of an innovation in inflation on expected future dividend growth. Many theories have argued for either a positive or a negative correlation of inflation with dividend growth $;^{38}$ the evidence suggests, if anything, a small positive effect throughout the sample. Putting this result and the previous one together, an innovation in inflation increases both the expected dividend yield and the expected rate of growth of dividends. Thus, on both grounds, it increases the expected rate of return on stocks. This is shown in the last column, which shows that an innovation in inflation of 1 percentage point is associated with a lasting increase in the expected rate of return on stocks of 0.1 to 0.2 percent.

The third result is interesting because it potentially reconciles the findings in the table with apparently contradictory findings by others that expected inflation has a negative effect on the rate of return on stocks. ${ }^{39}$ Note first that while the innovation in inflation and thus the capital loss in year 0 are both unexpected, once the innovation has been observed, the numbers for later years are expected by investors. The interesting number then is that for the expected capital loss in year 1 . Estimates from all but the first three subsamples (that is, the subsamples

37. Remember that the dividend yield is defined as the ratio of dividends during year $t$ to the price at the beginning of year $t$, so that only the numerator responds within year $t$.

38. For a review, see Ely and Robinson (1989).

39. See, for example, Fama and Schwert (1977). 
starting in 1929, 1930, and 1931) yield an anticipated capital loss in year 1 .

What this implies is that, in the year following the innovation in inflation, people can expect a higher dividend yield but also a further capital loss, which typically more than offsets the higher dividend yield. In other words, the expected one-year rate of return goes down after an increase in inflation. As we look at expected rates of return over longer holding periods, the higher dividend yield eventually more than offsets the anticipated capital loss. For the rate of return I have been focusing on in this paper, which corresponds to holding the stock forever, the expected rate of return depends only on the dividend yield and the rate of growth of dividends, and thus increases with inflation.

The expected capital loss following an innovation in inflation explains why the research that has focused on short holding period rates of return, typically from a month to a year, has found negative effects of expected inflation. This suggests that studies that looked at longer holding periods would find a positive rather than a negative effect; this is indeed what a recent study by Jacob Boudoukh and Matthew Richardson, which regresses five-year realized rates of return on expected inflation, has found..$^{40}$

Putting the results of this section together, innovations in inflation lead to a decrease in real bond rates- but only for a few years, at most; they lead to what appears to be a persistent increase in real rates of return on stocks. These results imply a relation between inflation and the premium that is stronger in the short run (while inflation affects real bond rates) than in the long run.

\section{Conclusions}

The two main conclusions of this paper are that the equity premium has gone steadily down since the early 1950s, and that inflation contributed to the transitory increase above trend in the 1970s and the transitory decrease below trend in the 1980s. Today, the premium appears to be around 2-3 percent. The results in the paper imply that, if inflation remains low, it should not be expected to move much from this current value.

40. Boudoukh and Richardson (1992). 
Figure 15. The Cost of Capital, 1929-93

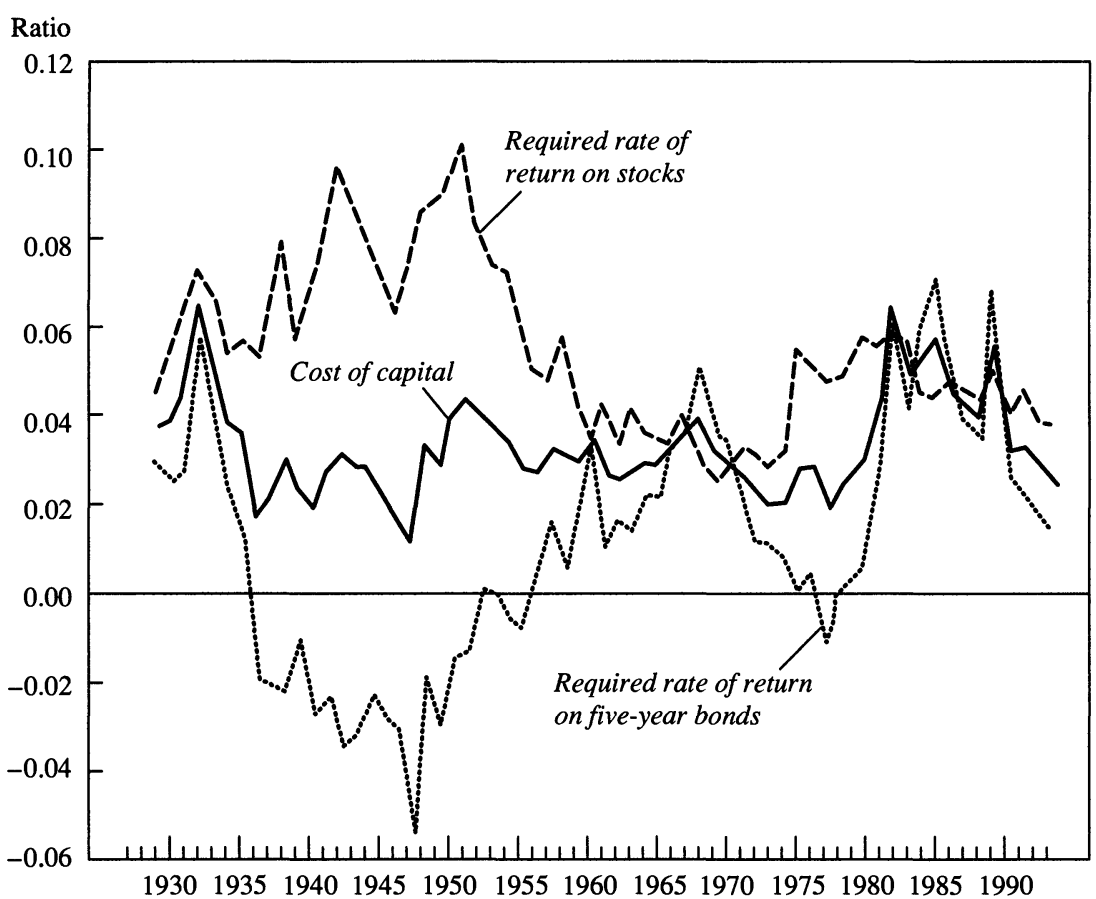

Source: See tables 2 and 3 .

a. The cost of capital is a weighted average of the expected rates of return on stocks and twenty-year bonds with equal weights of 0.5 for stocks and bonds.

This has a number of implications, not only for finance but also for macroeconomics. I shall briefly mention three. The first is that the financial component of the cost of capital has moved much less than its two underlying elements over the last sixty-five years. This point is made graphically in figure 15 , which plots an equally weighted average of the expected rates of return on stocks and twenty-year bonds, ${ }^{41}$ as well as its underlying components. The cost of capital so obtained appears nearly constant compared to the variations in expected stock and bond rates of return. Thus, in thinking of what happened in the 1970s or the 1980 s, for example, we should be wary of focusing primarily on real bond rates.

41. The weights are chosen for symmetry and I do not attempt tax corrections. The basic point made in the figure is obviously robust to the exact choice of weights. 
The second point is closely related. Decreases in the equity premium are likely to translate into both an increase in expected bond rates and a decrease in expected rates of return on stocks. This is indeed what I have shown. It is thus reasonable to anticipate higher real bond rates in the future than in the past.

The third point follows from the second. Firms that have access to both equity and bond finance may not be affected much by changes in the equity premium. But for those that have to rely only on debt finance, the change in equilibrium real bond rates is much more important. In particular, higher real rates on debt imply that governments may find it more dangerous and more difficult to rely on deficit and debt finance. The arithmetic of debt accumulation with low growth and high real bond rates has been painfully obvious in the recent past in many OECD countries. If real interest rates remain high, those lessons will have to be remembered.

\section{APPENDIX}

\section{Detailed Source Tables}

THE FOLLOWING TABLES provide detailed calculations and source material for tables, figures, and calculations in the text. Tables A1 and A2 show short-term and medium-term real interest rates, for the world and individual countries, from 1978-93. Table A3 provides information on the dividend yield from 1978 to 1992. 
Table A1. Short-Term Real Interest Rates, 1978-93

Percent

\begin{tabular}{lcccrrrr}
\hline Year & $\begin{array}{c}\text { United } \\
\text { States }\end{array}$ & $\begin{array}{c}\text { United } \\
\text { Kingdom }\end{array}$ & Germany & France & Italy & Japan & World $^{\mathrm{a}}$ \\
\hline 1978 & 0.3 & -4.7 & -0.9 & -1.2 & 1.0 & -2.1 & -0.8 \\
1979 & 0.6 & -0.8 & 1.3 & -5.9 & -2.2 & -0.2 & -0.4 \\
1980 & 0.0 & 1.0 & 2.7 & 0.0 & 0.3 & 0.4 & 0.5 \\
1981 & 0.8 & 3.9 & 6.0 & -1.5 & -0.9 & 2.7 & 1.6 \\
1982 & 5.8 & 4.2 & 6.8 & 1.5 & 5.5 & 2.7 & 4.8 \\
1983 & 2.9 & 5.4 & 4.6 & 0.4 & 6.4 & 3.9 & 3.4 \\
1984 & 5.2 & 3.5 & 4.9 & 4.9 & 3.6 & 5.1 & 4.9 \\
1985 & 4.2 & 5.6 & 3.4 & 4.1 & 4.0 & 4.1 & 4.1 \\
1986 & 3.3 & 7.0 & 2.1 & 4.2 & 7.8 & 2.1 & 3.5 \\
1987 & 1.0 & 7.1 & 5.2 & 6.3 & 3.9 & 3.3 & 3.1 \\
1988 & 1.4 & 4.7 & 1.5 & 4.9 & 4.1 & 2.0 & 2.3 \\
1989 & 3.3 & 5.0 & 2.8 & 5.3 & 5.6 & 2.4 & 3.5 \\
1990 & 3.5 & 8.1 & 4.1 & 6.3 & 7.9 & 4.7 & 4.9 \\
1991 & 2.0 & 9.6 & 5.1 & 6.3 & 4.5 & 4.6 & 4.1 \\
1992 & -0.2 & 5.6 & 5.1 & 7.3 & 6.1 & 3.1 & 2.7 \\
1993 & 0.4 & 4.2 & 4.9 & 9.4 & 7.1 & 2.0 & 2.8 \\
\hline
\end{tabular}

Source: For 1978-83, Blanchard and Summers (1984, table 2, p. 278). For 1984-93, nominal rates are from International Financial Statistics, line 60c for the United States, the United Kingdom, Germany, and Italy, and line $60 \mathrm{~b}$ for France and Japan. Inflation forecasts are from DRI, U.S. and European Reviews. Nominal rates are for the first month of each year. They are Treasury bill rates for the United States, the United Kingdom, Germany, and Italy, and money market rates for France and Japan. Real rates are obtained by subtracting DRI December forecasts of inflation for the first quarter of the following year.

a. The world rate is constructed using relative GDP weights at current exchange rates as relative weights for the six countries indicated above. 
Table A2. Medium-Term Real Interest Rates, 1978-93

Percent

\begin{tabular}{ccccccc}
\hline Year & $\begin{array}{c}\text { United } \\
\text { States }\end{array}$ & $\begin{array}{c}\text { United } \\
\text { Kingdom }\end{array}$ & Germany & France & Italy & World $^{\text {a }}$ \\
\hline 1978 & 2.2 & 0.1 & 1.4 & 2.4 & 4.5 & 2.1 \\
1979 & 2.1 & 4.5 & 2.4 & -0.1 & 1.1 & 2.0 \\
1980 & 1.0 & 4.1 & 3.3 & 3.2 & 1.9 & 2.0 \\
1981 & 2.2 & 2.1 & 4.9 & 3.9 & 1.8 & 2.7 \\
1982 & 6.9 & 5.3 & 5.7 & 3.3 & 7.4 & 6.3 \\
1983 & 4.3 & 2.3 & 4.0 & 6.3 & 5.1 & 4.3 \\
1984 & 6.5 & 3.3 & 3.9 & 5.1 & 3.8 & 5.7 \\
1985 & 6.2 & 5.8 & 4.6 & 4.3 & 3.2 & 5.6 \\
1986 & 4.6 & 6.7 & 3.7 & 4.2 & 6.5 & 5.8 \\
1987 & 2.4 & 6.7 & 4.0 & 5.6 & 3.2 & 3.5 \\
1988 & 3.4 & 4.7 & 3.5 & 6.9 & 3.7 & 3.9 \\
1989 & 4.1 & 4.9 & 4.1 & 5.2 & 4.1 & 3.3 \\
1990 & 3.4 & 7.2 & 5.3 & 6.8 & 6.8 & 4.8 \\
1991 & 3.7 & 6.4 & 6.1 & 6.7 & 5.8 & 4.9 \\
1992 & 2.7 & 6.0 & 4.9 & 4.9 & 3.2 & 3.6 \\
1993 & 2.5 & 3.1 & 4.3 & 5.2 & 6.6 & 3.5 \\
\hline
\end{tabular}

Sources: For 1978-83, Blanchard and Summers (1984, table 4, p. 280). For 1984-93, nominal rates for the United States, the United Kingdom, Germany, France and Italy, OECD Financial Statistics; line IIb2 for Italy, line IIb1 for the others. Inflation forecasts from DRI, U.S. and European Reviews. Forecasts for Japan were not available. Nominal rates are for the first month of each year. For the United States and the United Kingdom, on government bonds, in the secondary market, with five years to maturity. For Germany, on public bonds, in the secondary market, with three- to seven-year maturity. For France, on bonds in the secondary market with ten years or more maturity. For Italy, on "creditop" bonds, with five-year average maturity.

Real rates are obtained by subtracting forecasts of inflation over the life of the bond, as described in the text. The forecasts used are DRI forecasts of inflation, as of the previous December. The maturities are assumed to be five years for the United States, the United Kingdom, West Germany and Italy, ten years for France.

a. The world rate is constructed using relative GDP weights at current exchange rates as relative weights for the five countries indicated above. 
Table A3. Dividend-Price Ratios, 1978-92

Percent

\begin{tabular}{cccccccc}
\hline Year & $\begin{array}{c}\text { United } \\
\text { States }\end{array}$ & $\begin{array}{c}\text { United } \\
\text { Kingdom }\end{array}$ & Germany & France & Italy & Japan & World $^{\text {a }}$ \\
\hline 1978 & 5.3 & 5.5 & 3.2 & 6.7 & 5.0 & 1.6 & 4.4 \\
1979 & 5.4 & 5.6 & 3.7 & 5.7 & 3.4 & 1.6 & 4.5 \\
1980 & 5.4 & 6.7 & 5.7 & 6.3 & 2.5 & 1.6 & 4.7 \\
1981 & 5.1 & 6.1 & 5.7 & 8.1 & 2.0 & 1.5 & 4.7 \\
1982 & 5.8 & 5.6 & 5.5 & 7.9 & 2.3 & 1.7 & 5.0 \\
1983 & 4.4 & 4.7 & 4.0 & 6.6 & 2.4 & 1.4 & 3.9 \\
1984 & 4.6 & 4.5 & 3.6 & 5.2 & 3.1 & 1.1 & 3.9 \\
1985 & 4.3 & 4.4 & 3.3 & 4.0 & 2.9 & 1.0 & 3.5 \\
1986 & 3.6 & 4.1 & 2.7 & 2.6 & 1.6 & 0.8 & 3.7 \\
1987 & 3.1 & 3.3 & 3.3 & 2.9 & 1.9 & 0.6 & 2.4 \\
1988 & 3.6 & 4.1 & 4.0 & 4.0 & 2.6 & 0.5 & 2.9 \\
1989 & 3.4 & 4.2 & 3.4 & 2.6 & 2.4 & 0.5 & 2.7 \\
1990 & 3.6 & 4.8 & 3.1 & 2.9 & 2.8 & 0.5 & 2.8 \\
1991 & 3.3 & 4.9 & 3.6 & 3.5 & 3.7 & 0.6 & 2.9 \\
1992 & 3.1 & 4.8 & 3.7 & 3.4 & 3.9 & 0.9 & 2.8 \\
\hline
\end{tabular}

Sources: OECD Financial Statistics, various issues. Dividend-price ratios are yearly averages of quarterly values; quarterly values are for the first month of each quarter.

a. The world rate is constructed using relative GDP weights at current exchange rates as relative weights for the six countries indicated above. 


\section{Comments and Discussion}

Robert Shiller: What are we to make of the striking fact that the dividend-price ratio, observed in the world stock market, has declined substantially since the late 1970s-as shown in Olivier Blanchard's paper, in figure 3 or table A3? In the world bond market, a similar movement in real interest rates has not occurred, as figures 2 and 8 and table $\mathrm{A} 2$ indicate. Real long-term interest rates displayed a hump-shaped pattern over this period, and are still higher at the end of Blanchard's sample than they were in the late 1970 s. $^{1}$ The dividend-price ratio is often considered another sort of long-term real interest rate, so it might have been expected to move with the real long-term interest rate observed in bond markets, and to have shown the same hump-shaped pattern since the late 1970s.

But there is an important difference between the dividend-price ratio observed in stock markets and the real long-term interest rate observed in bond markets; the dividend-price ratio can be affected by expected growth rates of future dividends. Blanchard uses an economic model (his equations 1 through 4) to define long-term real interest rates from bond market data and to take account of this dividend-growth effect on stock market data; the model allows estimates to be made of the ex ante equity premium - the expected difference between real stock returns and real bond returns. This present value model allows this equity premium to be estimated without ever using the noisy data on actual returns in the stock market.

1. The opening line to Blanchard's paper suggests that real bond yields are now much higher than they were in the early 1980s; looking at the plots, I would rather emphasize the hump-shaped pattern of real rates since then; long real rates have come down a lot since the late 1980s. 
The assumption that this expected equity premium is constant through time has been discussed many times by other researchers. Making the left-hand sides of equations 1 and 3 equal up to a constant additive equity premium indicates that stock price movements (or dividendprice ratio movements) can be understood entirely in terms of changes in the rate of discount, as measured by interest rates, and changes in expected dividend growth rates. This model then interprets changes in dividend-price ratios as due to a rational response to new information about interest rates and information about future growth rates of dividends. This model has been tested and rejected by other researchers. Blanchard here goes a step beyond these studies and characterizes the time variation in the equity premium, and does this for the world stock market.

An important conclusion in this paper is that the decline in the spread between the dividend-price ratio in the world stock market and the real interest rate in the world bond market since 1980 appears unreconcilable with this present value model. To reconcile that spread with this model, one would need to assume that the expected future annual growth rate of real dividends was about 4.7 percent higher in 1990 than in 1980; Blanchard states that there is no reason for people to expect such higher dividend growth now. I would certainly agree with that view; this is just another manifestation of the extraneous volatility of the dividend-price ratio that John Campbell, Andrea Beltratti, and I documented. ${ }^{2}$ The dividend-price ratio has historically moved around largely independently of the fundamentals defined by the present value model. Low dividendprice ratios relative to interest rates are, in this model, supposed to forecast increases in dividends; in practice these forecasts implicit in the dividend-price ratio have been very wild. Indeed, dividend-price ratio movements appear to be due to something endogenous to the stock market.

Blanchard's conclusions about the movements in the equity premium are not obvious to someone eyeballing the usual data; his analysis of his model, in equations 1 through 4 , is essential to understanding his conclusion. Someone looking at the usual data would probably note first that nominal interest rates have come down a lot since the early 1980s and might think that this is a good reason for stock prices to go up and divi-

2. Shiller and Beltratti (1992) and Campbell and Shiller (1988). 
dend-price ratios to decline. Doesn't the booming stock market make sense from the lower nominal interest rates? This interpretation appears daily in newspapers and other popular media. Blanchard is more careful than the media; recognizing that the dividend-price ratio is more like a real long-term rate than a nominal long-term rate, he compares it instead with his constructed real long rates. He constructs these, quite appropriately, by running the regressions of his constructed actual inflation variables $A \pi^{5}$ and $A \pi 20$ (created using his model, from equation 2 ) onto forecasting variables in his tables 1 and $2 .^{3}$

While the later 1980s were a period when world nominal interest rates were falling sharply from their peak in the early 1980s, real long-term rates were unusually high throughout this period. Hence, the decline in nominal rates in the later 1980 s can be attributed entirely to declines in inflationary expectations, and hence this decline is not a reason, in the context of the rational model presented here, for the decline since the early 1980s in the dividend-price ratio.

This conclusion does not rule out that the decline in the dividendprice ratio might have something to do with the decline in nominal interest rates if people are irrationally overreacting to the declines in nominal rates. That the stock market may be substantially influenced by such irrational overreactions was hypothesized first by Franco Modligiani and Richard Cohn in 1979. ${ }^{4}$ The current decline of both dividend-price ratios and nominal long rates would appear to provide some new out-of-sample confirmation of their theory, and an interpretation of one of the causes of the excess volatility of dividend-price ratios.

One reason why Modigliani and Cohn's paper has not received more attention, I think, is that, by advancing an explicitly behavioral hypothesis about the stock market, it cannot be easily tested. Once one recognizes that there is such a behavioral component to stock prices, then one would naturally also recognize that there are other judgment errors that people make in their pricing of the stock market. Thus the model is not tight; the observed correlation of nominal rates with dividend-price ra-

3. Note that the long-term interest rate sometimes gets a negative sign in Blanchard's regressions of long-term inflation on information variables, as seen in the lower panel of table 2. Such wrong signs have a long history. The term "Gibson paradox" coined by Keynes refers to a tendency for positive correlation between long-term interest rates and price levels. Since price levels have historically shown some tendency for mean reversion, price levels were negatively correlated with subsequent inflation.

4. Modligiani and Cohn (1979). 
tios cannot give any impressive confirmation of Modigliani and Cohn's hypothesis.

Modigliani and Cohn's paper can be improved by making corrections in the dividend-price ratio for forecastable changes in future dividend growth rates. This is essentially what Blanchard does in this paper, in the lower panel of table 4 . The dependent variable is the ex post equity premium as he defines it; it is found to be strongly negatively related to the nominal long rate. His evidence is analogous to the evidence that Beltratti and I found for the United States and the United Kingdom; there does appear to be an overreaction of dividend-price ratios to nominal long rates. ${ }^{5}$

Of course, I am not quite justified in using the word "overreaction," since correlation does not prove causality. To me, the most impressive evidence in Modigliani and Cohn's paper that the market really overreacts to nominal interest rates was their evidence from memoranda from large brokerage firms advising institutional investors about the level of the market and interest rates; they found that the fallacious use of nominal interest rates was widespread. If such errors are widespread among these memoranda, then surely the errors are being made by many other market participants. This evidence also suggests that there might be a correction in the stock market should nominal interest rates increase.

Let me comment briefly on the use of the the data on British indexlinked gilts. The idea that the market for indexed debt in the United Kingdom measures the same long-term real interest rate under discussion here neglects to observe that the index-linked gilts are very different instruments from the nominal bonds used elsewhere in this paper; they guarantee a real coupon. There is likely to be a substantially different market for such an instrument, and the yields in this market are affected by supply and demand for these particular bonds. The amount issued of U.K.-indexed bonds is a decision of the British government. If they issued very few, then the yields would be very low, since the most eager buyers would bid their prices up. We know in principle that the real rate on the bonds they issue depends on the number of bonds that they issue, even though it is hard to get any empirical evidence to confirm this, just as it is hard to get empirical evidence to confirm that the yield spread between shorts and longs is affected by decisions of how

5. Shiller and Beltratti (1992). 
much to issue at the various horizons. Still, the decisions in the United Kingdom about how much to issue have more impact on their market because they have the only major indexed debt long-term market.

Let me conclude by trying to offer some interpretation of the current low dividend-price ratio that seems so inexplicable after reading the Blanchard paper. Offering such an interpretation is inherently risky.

It would seem that an important factor now in the low dividend-price ratio around the world relative to ten years ago would certainly be the relatively low nominal interest rates, given the judgment errors documented by Modigliani and Cohn. But, possibly, other factors, even less easily quantified, are also at work. I have stressed in my own work that because people talk to one another about investments, there is a tendency for attitudes and ideas to drift through time. Furthermore, because people talk to people around the world, these new attitudes and ideas spread around the world.

The reason that different countries experience similar movements in their dividend-price ratios must surely have something to do with the fact that investors in these countries are looking at one another, using one another as examples. The same thing happens at the time of a stock market crash. Surely, the tendency for stock markets around the world to crash at the same time has something to do with people looking at one another's emotional or intuitive reactions to events; by the same token, the tendency for dividend-price ratios to show similar movements has somewhat of the same social origin.

If we were all independent, each of us taking a fresh look at all the basic facts regarding the stock market and forming an independent opinion about how much stock to hold, then the law of large numbers would seem to imply that people would not change their opinions except in response to some basic and important change in the facts. In practice, people are not independent; there is a collective attention and collective memory around the world.

The sociologist Maurice Halbwachs coined the term "the collective memory" to refer to memories that society has in common and that continue to persist by constant reinforcement through social communication. ${ }^{6} \mathrm{His}$ argument is that each of us hears vastly more information than our brains could possibly store, we forget almost everything we hear, 
and only memories that are consistently reinforced remain. An important reinforcing mechanism is social interaction. For an example of the importance of such reinforcing, think back on some movie that you saw only once years ago. How much do you really remember? Don't you tend to remember the scenes that people discussed later? Do you remember the line "Play it again, Sam"? For most of us this one line is the only concrete dialogue from the movie "Casablanca" that we remember. Why do so many of us remember that same line? It must be because it is replayed for us again and again. Actually, this line is not even in the movie; it entered the collective memory as the result of some strange mistake. ${ }^{7}$ All of the actual dialogue of the film has disappeared from the collective memory, to be replaced by this artifact. This example illustrates how quixotic and selective the collective memory is.

The memory of the crash of 1929 and the Great Depression-which Blanchard notes is gradually fading-is part of the collective memory. It has reached the importance of a folk legend. The legend concentrates on the Black Monday, October 28, 1929, when the Dow Jones Industrial Average fell 12.8 percent in a single day. (It fell an additional 11.7 percent the next day.) But this memory is capricious. How many people remember that the market rallied on Wednesday and Thursday, to close on Thursday, October 31, 1929, only 8.5 percent below its close the preceding Friday? Black Monday was a temporary blip in the index. If one looks at a plot of the data, the real event that stands out is the gradual decline from 1929 to 1932: an 89.2 percent decline from the close on September 3,1929, to the close on July 8, 1932. But that gradual decline is not what people remember. And how many people remember the 93.9 percent increase in the Dow from July 8, 1932, to September 7, 1932? The truth is, there are vast numbers of interesting stories in the data: the complexity of the story told by these numbers-as in any economic time series-is mind-boggling. Similarly, the impressions and recollections that are in the collective memory are inevitably capricious and selective.

How much stock should one hold if the dividend-price ratio is 2 percent? If it is 3 percent? If it is 5 percent? Unfortunately, there is no clear answer. There are millions of facts about the stock market, and no clear theoretical framework to hang them on that would allow one to answer these questions. One must somehow make a decision about how much

7. The mistake may be due to Woody Allen, who made a movie in 1972 entitled "Play It Again, Sam." 
stocks to hold in one's portfolio-and such decisions collectively determine the level of stock prices. When there is no clear, objective theory about how to make this choice, it is inevitable that people, being what they are, will be buffeted by social forces and influenced by overly simple comparisons. When the decision about how much stock to hold is so tenuous, people will try to make up their minds with some intuitive judgment, which means that they will fall back on those facts and theories that they know and remember well.

What are the changing popular models that are in vogue that have had an impact on the level of stock prices? Let me go out on a limb and give a theory based on casual impressions. A trend in social thought that I think can be discerned is an increasing awareness of the fact that stocks have generally outperformed fixed income and other investments. The public cannot absorb complicated theories, and a theory that one class of investments is just the best class is one that is so simple that it may easily obtain some currency. Real estate used to be an investment that was so regarded by many people; the idea that land prices could only go up was widely remarked upon in Japan; the theory had even had a name there, the "land myth." But recent declines in real estate prices have tarnished this popular theory. If the theory that stocks have always done well is increasingly finding its way into the collective memory, then it ought to raise stock prices relative to dividends. I do not have any proof that awareness of this is increasing, but I did try to confirm that awareness of this fact is substantial today. As part of the semiannual surveys of investment managers that Fumiko Kon-Ya, Yoshiro Tsutsui, and I have been conducting, I asked U.S. respondents to tell me if they have heard something like the claim that there has been no thirty-year period in U.S. history since 1860 when U.S. government securities had outperformed stocks. ${ }^{8}$ (Note that this observation appears in a slightly different form in Blanchard's paper.) Of the 125 responses I received from $\mathrm{Au}-$ gust through October 1993, 52 percent of respondents said that had heard such a story often, and an additional 22 percent said that they had heard it once or twice. (Twenty-six percent said they had never heard it.) Only if we continue to conduct surveys can we learn whether this story is growing in the collective memory, and only if we ask in other countries can we confirm its international currency.

8. For a description of these surveys see Shiller, Kon-Ya, and TsuTsui (1992). 
We do have some short time series on social thought that suggest reasons behind the decline in the dividend-price ratio. One of our questions asked respondents whether they agreed with the statement, "Although I expect a substantial drop in stock prices in the U.S. ultimately, I advise being relatively heavily invested in stocks for the time being because I think that prices are likely to rise for awhile." This question was intended to get at a sort of speculative motive for holding stocks. The wording of this question has been criticized; it is hard to know what a no answer means. But we are stuck with this question as it reads if we want to have a time series. Of the 127 U.S. respondents who answered this question in our August-October 1993 survey, 31 percent chose yes, compared with 12 percent a year ago. But the recent sample is not much different from the 34 percent who chose yes in mid-1989. The difference from 1989 is that, in response to a question that asked respondents to choose whether the stock market was "too low," "too high," "about right," or "do not know," the percent picking too high is now 43 percent, (and the percent choosing too low is 2 percent), compared with only 19 percent that picked too high (and 16 percent that chose too low) in mid1989. This evidence is consistent with a view that the rise in the market since 1989 is substantially speculative. Further confirmation of this view is found in the fact that now, when asked to give the probability of a crash in the next six months, respondents estimate an average probability of 21 percent, compared with 15 percent in mid-1989. The origins of opinions about the short-run course of the market are especially hard to understand; as regards attempts to time the market, people are playing a game against one another, watching one another closely and trying to make their move first. No one could expect to easily understand and model the outcome of such a game.

Summing up these ideas to explain the low dividend-price ratio, I can think of three possible theories: the overreaction to low nominal interest rates; the growing popular notion that stocks have always outperformed other investments; and a speculative feeling that the market will go higher for a while.

Jeremy J. Siegel: The equity premium, formally defined as the expected arithmetic return on equity in excess of the "risk-free" asset, is a topic that is of importance to both investors and economists. The size of the premium-8.0 percent since 1926 and 6.5 percent since 1871 -ap- 
pears far in excess of what is justified by standard asset-pricing models with reasonable levels of risk aversion, given the behavior of the variance-covariance matrix of historical returns on bonds, stocks, and consumption. The unexplainably large size of the premium has been termed the "equity premium paradox."

Many modifications to the standard finance model have been proposed that may help explain the high level of the equity premium, and these are amply cited in Olivier Blanchard's paper. But the author tackles the premium from another standpoint, arguing that the large excess return is due primarily to an unusual period from the Great Depression through the early 1970s, which may not be typical of longer periods, historically or prospectively. Furthermore, Blanchard maintains that there is evidence that looking ahead, th $\approx$ equity premium will stand closer to the far lower levels that existed in the nineteenth and early twentieth century.

These are views to which I am quite sympathetic and about which I have written extensively. ${ }^{1}$ Discussion figures D1 and D2 plot thirty-year moving averages since 1802 of historical annualized arithmetic real returns on stocks and bonds, and the difference between the two. Discussion table D1 summarizes real stock and bond returns and the equity premium for various subperiods.

Several important inferences can be drawn from these data. The first is that the trend of the average real return on stocks has remained remarkably constant through the last two centuries, while the real returns on fixed-income assets collapsed during most of the twentieth century. During the period when bond returns were very low, stock returns were indeed high, but not that much higher than they had been in the past.

Some authors have noted that the paradox is more of a real rate paradox than an equity premium paradox. In other words, it is the unusually low real rates on fixed-income assets that is more difficult to explain than the high return on equity. In fact some of the increase in equity returns during the immediate postwar period might well be explained by the low returns on fixed-income assets, which allowed firms to leverage their capital stock cheaply. I fully agree with Blanchard that the total cost of capital did not change markedly during the period; what changed was the relative magnitude of bond and stock returns.

1. See Siegel (1992a, 1992b, and 1994, forthcoming). 


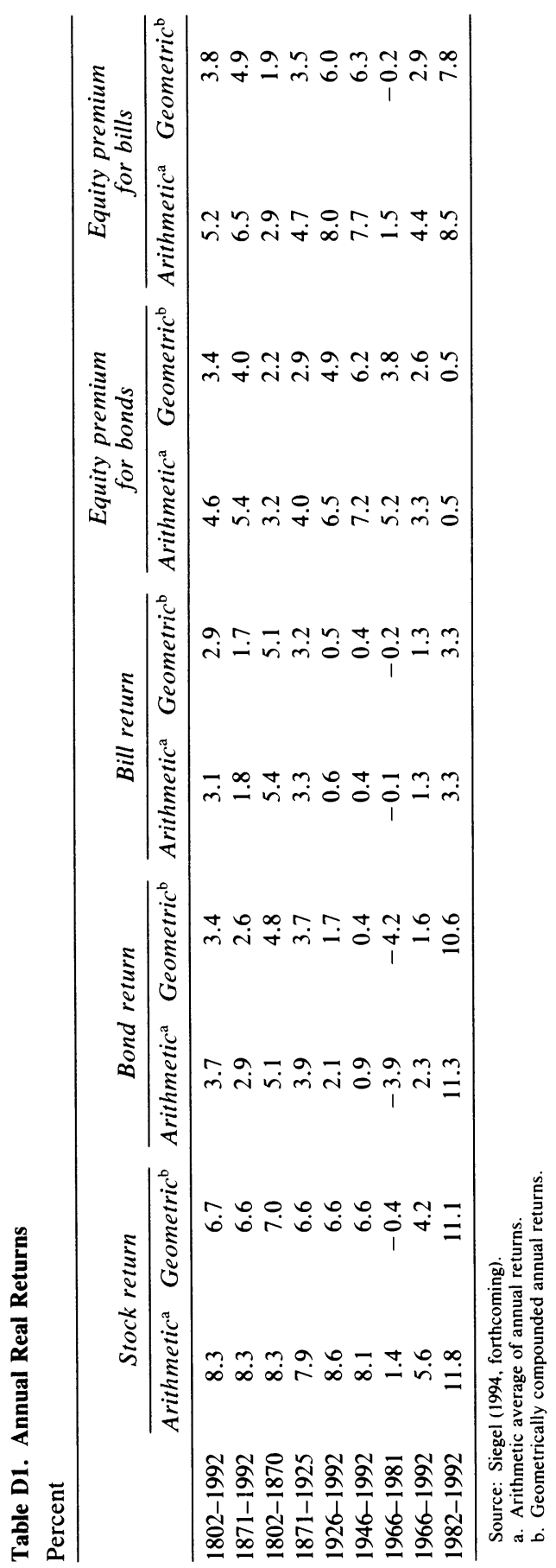


Figure D1. Real Returns on Stocks, Bonds, and Bills ${ }^{a}$

Percent

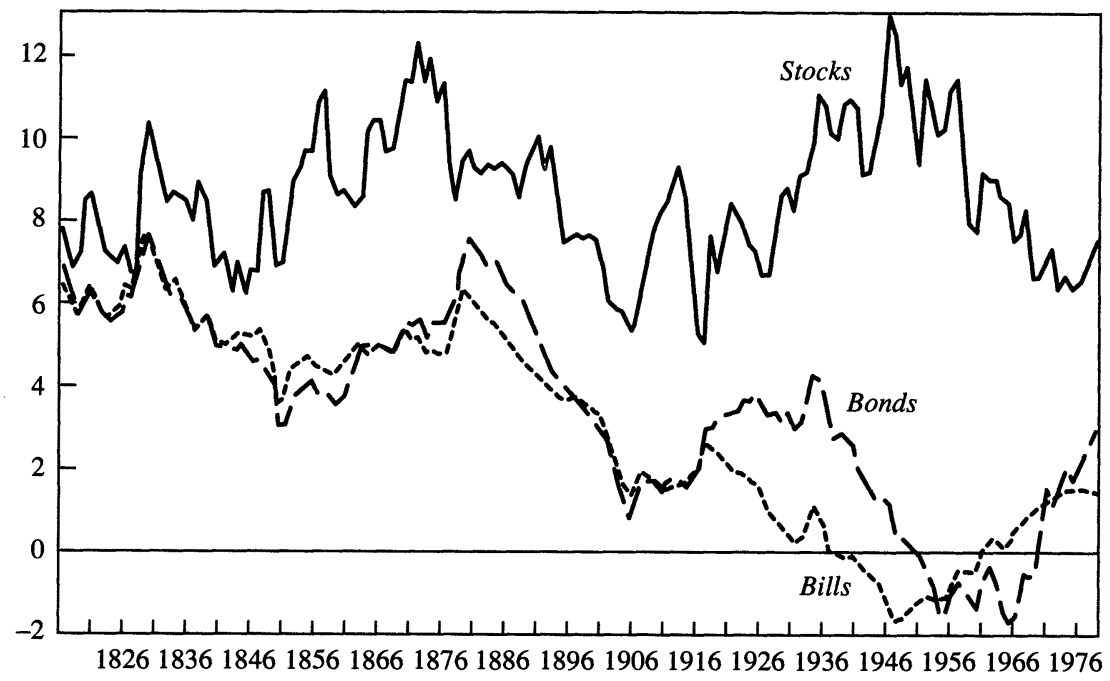

Sources: Siegel (1992b; 1994, forthcoming).

a. Thirty-year centered arithmetic moving average (1816-1977).

Figure D2. Equity Risk Premium ${ }^{a}$

Percent

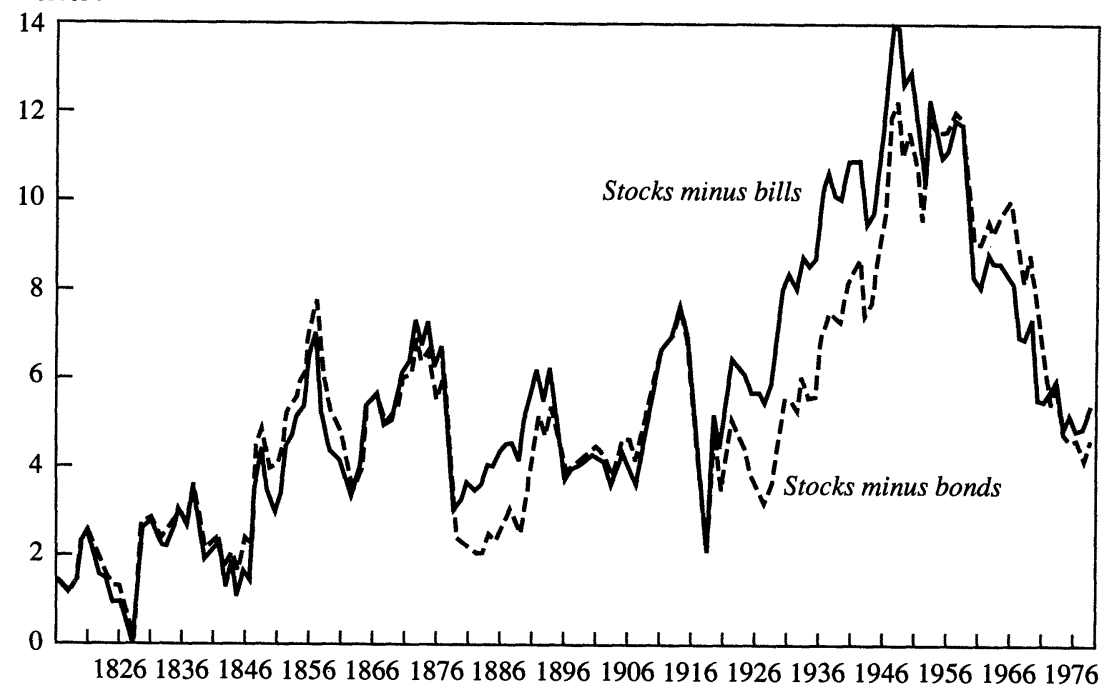

Sources: Siegel (1992b; 1994, forthcoming).

a. Thirty-year centered arithmetic moving average (1816-1977). 
Although the high returns on equity in the postwar period might be explained as result of the undervaluation of stocks following the great 1929-32 stock crash, as Blanchard suggests, it is more difficult to explain the collapse of the real return on fixed-income assets, particularly of short-term bonds. I believe that one of the reasons is that market participants (as well as most economists) did not fully recognize the significance of the changes that were taking place in the monetary system during and after the Great Depression. The progressive demonetization of gold and the movement toward a paper money standard set the stage for the postwar inflation. Yet during the war, most investors and economists predicted that another depression would occur when government military demands ceased. These investors bought bonds in anticipation of the deflation that had followed every previous war.

The fact that the postwar inflation drastically reduced real long-term bond returns is well known. However, it is a puzzle why holders of Treasury bills did not appear to catch up to the inflationary bias of monetary policy, given the general inertia of the inflationary process. Investors may still have entertained regressive expectations of inflation, misunderstanding the nature of the new monetary system. Perhaps the pegging operations of the Federal Reserve and deposit rate controls were a factor, although these explanations may not be consistent with flexible price macroeconomic models.

Clearly by the 1970s, and especially the 1980s and 1990s, bondholders had caught on to the inflationary bias that exists under a fiat money system. If unanticipated inflation is the primary reason for the equity premium puzzle, then the premium may return to a level similar to that in the previous century, if inflation remains low, as it has during the 1990s. A lower equity premium would result from either an increase in future real bond returns or a reduction in future equity returns, or both.

As of early September 1993, the thirty-year zero coupon bond was selling at a yield of about 6.2 percent. Assuming a 4 percent average annual compound rate of inflation over the next thirty years, the real return on these bonds would be 2.1 percent (allowing for the cross-product term of the Fisher equation). A 3 percent average inflation yields a 3.1 percent real return on a thirty-year fixed income security. The latter is closer to the real returns on indexed securities in the United Kingdom.

There are two ways to compute the future real return on equity. The first is to determine the average earnings yield on stocks, corrected as 
well as possible for cyclical factors. I have collected a survey of expected earnings estimates from a group of analysts on the S\&P 500 index for 1994 . The average is about $\$ 28$ per S\&P share. Given that the current index is 460 , this results in a 6.1 percent real return. It should be noted from discussion table D1 that the average real compound annual return on equity has been remarkably stable over the past two centuries, fluctuating between 6.6 percent and 7.0 percent over the major subperiods, so the prospective yield now is a little lower than average.

A second way to estimate the real expected return on equity is to take the current dividend yield and add the expected growth rate of dividends. The 1994 projected dividend payout on the S\&P 500 index is $\$ 13.32$, which, at current levels of the index, is a 2.9 percent return. This is extraordinarily low on a historical basis. However, this dividend represents less than one-half of the estimated earnings on the S\&P 500 index. If this payout ratio ( 48 percent) is maintained, and the firms in the S\&P 500 index earned 6.1 percent on retained earnings, this would result in a dividend growth rate of about 3.2 percent per year, so that the total return would be 6.1 percent. Of course, this is a simple application of the principle that the return on shares (excluding taxes) is independent of the dividend payout ratio.

It should be noted that a dividend growth rate of 3.2 percent would be high by historical standards. Since World War II, real dividends on the S\&P 500 index have increased by only 2.0 percent per year. But during most of the time the dividend payout ratio was higher, which may explain why the past dividend growth rate was lower. ${ }^{2}$

Blanchard believes that 2 percent is a better estimate of future dividend growth. Based on historical patterns, this may be true. But there are several factors that may argue for higher growth. First is the relatively low dividend payout ratio, and second is the high "quality" of current earnings. By quality I mean that firms now are experiencing very high cash flows relative to reported earnings. The nearly record low inflation of capital goods (information system costs are declining at a record pace) has reduced economic depreciation, so that reported earn-

2. Many researchers, such as Eugene Fama and Kenneth French, have noted that the real return on stocks is negatively dependent on the dividend payout ratio. But this is mostly for intermediate-term horizons, such as five years. My own preliminary research indicates that over thirty-year horizons, the real returns on stocks appear little affected by the dividend yield. 
ings are lower than true economic earnings. Furthermore, international growth prospects are bright and firms are cutting costs aggressively. So long-term dividend growth may well exceed the 2 percent postwar figure.

Taking a middle ground between the 3.2 percent growth derived from dividend and earnings and the 2.0 percent historical rate yields a 2.6 percent real growth of dividends. Combined with a 2.9 percent dividend yield, this gives a 5.5 percent return. Assuming that the long-term inflation rate remains between 3 percent and 4 percent per year, then the current real yield on long-term fixed income assets is between 2.1 percent and 3.1 percent. This leaves the equity premium between 2.4 percent and 3.4 percent and much more in the ballpark of the equity premium derived from 1802 through 1926. So again, I agree fully with the author that future equity premium is apt to be much smaller than what was experienced over the past sixty-seven years. Whether this lowers the premium sufficiently to explain the equity premium paradox or real rate paradox is still unanswered.

One must be careful determining the difference between the arithmetic equity premium and the geometric premium. Finance theory derives the equity premium in arithmetic terms, since risk is traded off against per period expected returns. So when using long horizons, one should convert from average annual compound, or geometric returns, to arithmetic returns. This requires an estimate of the variance of returns, since the arithmetic return exceeds the geometric return by one-half the variance. Since stocks are far more volatile than bonds on an annual basis, the premium measured in arithmetic terms is between 100 and 200 basis points higher than that measured in geometric terms.

It should be further noted that when expected real returns are declining, the prices of existing financial assets will be rising. For example, if investors progressively lower their expectations of future interest rates, the price of long-term bonds will rise. Measured ex post returns on bonds will be high, although ex ante returns are falling. Many claim that this is happening now, sparking the current rallies in the stock and bond market. This signals lower returns for the rest of the decade.

The difference between the ex post and ex ante returns means that measurements of these two returns are apt to be out of phase. In the long run, however, the average of the ex post and ex ante should converge. But researchers should be cautioned about extrapolating recent past re- 
turns trends into the future since there are good economic reasons why future returns might be negatively correlated with current returns.

Blanchard also notes that the equilibrium premium depends not only on the variability of returns (and consumption) but also on the covariability of returns. Blanchard finds no trend in the covariability between stock and bond returns. This may well be true over short horizons, but I would be surprised if it held over longer horizons, especially prospectively. If economic growth slows, especially in response to a supply shock, and the government tries to stimulate the economy by expanding the money supply, then both stocks and bonds would suffer. Furthermore, a slowing economy would increase the budget deficit, which could eventually lead to monetization of government debt and higher inflation.

These considerations would make the future covariance between stock and bond returns more positive than it has been historically, when the world was on a gold standard and control of the money supply was largely independent of the central bank. In equilibrium this would lead to a lower equity premium, as bonds lose their ability to hedge against recessions accompanied by falling prices. It should be noted that the returns on British indexed and nonindexed debt cannot be used to derive the expected rate of inflation, but the expected inflation rate corrected for these correlation factors. If poor economic activity is correlated with higher inflation, the difference between the yield on nominal and indexed debt would overstate the expected rate of inflation.

If there is one part of the Blanchard paper that I might quibble with, it is the last paragraph. Whether the government budget deficit raises real rates is still hotly debated among economists and is not examined in the paper. Blanchard states that high real rates hurt those industries dependent on debt finance. Certainly that is true if the high real rates were caused by government monetary or fiscal policy. But I believe that the high real rates of the 1980 s were a result of the enormous demand for funds in the highly leveraged sectors of the private economy, particularly real estate. Yet the high real rates of the 1980 s did not seem to hurt that sector at all. In fact, prices of real estate boomed, and housing construction, especially in the commercial area, reached an all-time high.

One explanation for this phenomenon was the 1981 Tax Act, which offered accelerated depreciation schedules, among other benefits, to the real estate sector. This, combined with other factors, drove private credit and real rates to very high levels. The total collapse of the real rate 
in the United States over the past several years has corresponded almost precisely with the real estate bust. The bottom line is that high real rates may be caused by a boom in the debt-financed sector and not motivated by policy at all.

In summary, it is still likely that the returns on equity are higher than can be justified by standard finance models, even looking prospectively. But I also agree with Blanchard that there were special factors over the last half century that bloated the premium. Over the next several decades, stocks are still likely to outperform bonds, but by a margin considerably smaller than since either 1926 or World War II.

\section{General Discussion}

Several panel members contrasted Olivier Blanchard's results with the conventional view of expected stock returns. Greg Mankiw noted that the paper's estimates of expected returns are more pessimistic than suggested by the historical stock returns analyzed by Jeremy Siegel. Blanchard's results indicated that, looking ahead, the expected return is about 4 percent. In contrast, Siegel's results show that the real return on stocks, averaged over any thirty-year period since 1816 , never falls below 5 percent. If correct, Blanchard's prediction of a "new world," unlike anything in the past, has profound implications for long-term investors. Mankiw also noted that Blanchard's figures contrast starkly with projections of Wall Street forecasters, who continue to anticipate robust increases in earnings.

William Nordhaus commended Blanchard's focus on ex ante returns and noted how different his forecasts can be from forecasts based on recent ex post returns. For example, an unexpected fall in the discount rate will result in unexpected and high ex post returns; extrapolation of these returns suggests future expected returns are high, when in fact they are low. In spite of the merit of Blanchard's approach, Nordhaus believed that portfolio managers are likely to persist in using the ex post approach. He observed that the magnitude of the risk premium on a wide variety of assets, including physical capital, farmland, real estate, investment in energy conservation, and consumer durables, are comparable to the equity premium examined by Blanchard. The puzzle is not why the stock equity premium is so large, but why such a wide range of 
assets have expected returns so much larger than the return expected on bills or bonds. This suggests that the explanation of the puzzle is not likely to be found in special features of the stock market.

The panel also focused on the implications of Blanchard's results for macroeconomics and for business finance. Ben Bernanke wondered how to square Blanchard's results with firms' financing decisions in the 1980s. Blanchard's results suggest that equity became cheaper relative to debt in the 1980s. Yet firms relied more on debt and less on new issues. This raises the question of whether, as suggested in the paper, causation typically runs from the cost of alternative sources of funds to patterns of finance. Bernanke noted that the conventional wisdom during the 1980s was the reverse; in that period, firms used debt to retire equity, presumably boosting the price of their stocks and raising bond rates. Blanchard replied that this explanation could not explain long-term movements in the premium.

Ned Phelps questioned the suggestion that the cost of capital-including both debt and equity - rose much less in the 1980s than indicated by the increase in real interest rates. Phelps noted that new equity issues are quantitatively small, perhaps reflecting the moral hazard problems in financing new investment with new equity. The large weight on equity in the estimates of the cost of capital reflects not new issues but retained earnings. Phelps suggested that counting internal finance as 100 percent equity finance may be inappropriate. Some of the internal finance may simply be used to retire debt earning the bond rate; paying out the earnings would be similarly valued if shareholders receiving dividends turned around and invested them in bonds. Thus, the bond rate may be closer to the opportunity cost of retained earnings for shareholders. George Perry disagreed with Blanchard's characterization of pension funds as long-term investors. Pension funds hope to be in business for the long term; but they need to explain themselves to clients every three months, leading many to have high turnover and short horizons.

The construction of the expected stock return series generated substantial discussion. Chris Sims raised the possibility that the rolling regressions used to forecast inflation and dividend growth would generate forecasts that are too volatile, and that a rational investor would not use these forecasts in an undiscounted fashion. In any case, he suggested that Blanchard's results are likely to be sensitive to the technique used for forecasting inflation and dividend growth. Sims wondered whether, 
given the likely magnitude of standard errors, expected inflation and dividends have statistically significant effects on the equity premium. Sims also noted that the ex ante returns matched the ex post returns at the beginning of the period but not at the end, and offered a possible explanation. For the first forty years, the expected return series is calculated using regressions fitted to the whole forty-year sample, while the rest of the forecasts are taken from rolling regressions. Blanchard replied that his results were robust to alternative ways of treating the earlier period. Nordhaus noted that expected future dividends, treated as the determinant of stock prices, depend on future earnings and payout ratios. To avoid the need to forecast future earnings, he proposed the dividend payout ratio as a predictor of dividend growth. But Blanchard reported that the dividend-payout ratio did not work well as a predictor.

Robert Hall noted that the Livingston survey of six-month expectations for the $\mathrm{S} \& \mathrm{P} 500$ provides a direct estimate the expected return to stocks without any econometrics and wondered how those expectations compared with Blanchard's estimates. He also noted that Blanchard's procedure for measuring expected returns was similar to that used in earlier work by William Brainard, John Shoven, and Laurence Weiss reported in BPEA. Hall believed that this approach provides much more reliable answers than the "finance" approach, as exemplified by Rajnish Mehra and Edward Prescott's work. He argued that there is an advantage to focusing on the levels of prices, as in these papers, rather than on first differences if, as Hall believed, the equity premium is mean-reverting. 


\section{References}

Barsky, Robert B. 1987. "The Fisher Hypothesis and the Forecastability and Persistence of Inflation." Journal of Monetary Economics 19(1): 3-24.

Bernartzi, Sholomo, and Richard M. Thaler. 1993. "Myopic Loss Aversion and the Equity Premium." Unpublished paper. Cornell University (January).

Blanchard, Olivier J., and Lawrence H. Summers. 1984. "Perspectives on High World Real Interest Rates." BPEA, 2:1984, 273-324.

Boudoukh, Jacob, and Matthew Richardson. 1992. "Stock Returns and Inflation: A Long Horizon Perspective." Unpublished paper. New York University Business School.

Campbell, John Y. 1987. "Stock Returns and the Term Structure." Journal of Financial Economics 18 (2): 373-99.

— Variance Decomposition for Long-term Asset Returns." Unpublished paper. Princeton University (June).

$\rightarrow$ Campbell, John Y., and Robert J. Shiller. 1987. "Cointegration and Tests of Present Value Models." Journal of Political Economy 95(5): 1062-88.

$\longrightarrow \rightarrow$ 1988. "Stock Prices, Earnings, and Expected Dividends." Journal of Finance 43(3):661-76.

$\rightarrow \rightarrow$ 1989. "The Dividend Price Ratio and Expectations of Future Dividends and Discount Factors." Review of Financial Studies 1-3: 195-228.

$\rightarrow$ Cutler, David M., James M. Poterba, and Lawrence H. Summers. 1990. "Speculative Dynamics." Review of Economic Studies 58(3): 529-46.

Ely, David P., and Kenneth J. Robinson. 1989. "The Stock Market and Inflation: A Synthesis of the Theory and Evidence." Economic Review, Federal Reserve Bank of Dallas (March): 17-29.

Evans, Martin D., and Karen K. Lewis. 1993. "Do Expected Shifts in Inflation Affect Estimates of the Long-run Fisher Relation?" Unpublished paper. New York University (March).

$\rightarrow$ Fama, Eugene F. 1975. "Short-Term Interest Rates as Predictors of Inflation." American Economic Review 65(3): 269-82.

Fama, Eugene F., and Kenneth R. French. 1988. "Dividend Yields and Expected Stock Returns." Journal of Financial Economics 22(1): 3-25.

Fama, Eugene F., and G. William Schwert. 1977. "Asset Returns and Inflation." Journal of Financial Economics 5(2): 115-46.

French, Kenneth R., and James M. Poterba. 1991. "Were Japanese Stock Prices Too High?” Journal of Financial Economics 29(6): 337-63.

Gordon, Myron J. 1962. The Investment, Financing and Valuation of the Corporation. Homewood, Ill.: Richard D. Irwin.

Halbwachs, Maurice. 1950. La Memoire Collective. Paris: Presses Universitaires de France.

Ibbotson Associates. 1992. "Stocks, Bonds, Bills and Inflation." Chicago: Ibbotson Associates.

$\rightarrow$ Kahneman, Daniel, and Amos Tversky. 1979. "Prospect Theory: An Analysis of Decisions Under Risk.” Econometrica 97(March): 263-92. 
MaCurdy, Thomas, and John B. Shoven. 1992. "Accumulating Pension Wealth with Stocks and Bonds." Working Paper. Stanford University (January).

Malkiel, Burton. 1990. A Random Walk Down Wall Street. Norton.

Mauro, Paolo. 1992. "Relative Returns on Stocks and Bonds: A New Puzzle?" Unpublished paper. Harvard University (December).

McCallum, Bennett T. 1984. "On Low-Frequency Estimates of Long-Run Relationships in Macroeconomics." Journal of Monetary Economics 14(1): 3-14.

$\rightarrow$ Mehra, Rajnish, and Edward C. Prescott. 1985. "The Equity Premium: A Puzzle." Journal of Monetary Economics 15(2): 145-61.

Modigliani, Franco, and Richard A. Cohn. 1979. "Inflation, Rational Valuation and the Market." Financial Analysts Journal: 3-23.

Mullins, Mark, and Sushil Wadhwani. 1989. "The Effects of Inflation and Interest Rates on Stock Returns: Evidence from Three Centuries of UK Data." Discussion Paper 72. London: London School of Economics, Financial Markets Group.

$\rightarrow$ Shiller, Robert J. 1981. "Do Stock Prices Move Too Much to Be Justified By Subsequent Changes in Dividends?" American Economic Review 71(3): 42136.

and Andrea E. Beltratti. 1992. "Stock Prices and Bond Yields: Can Their Comovements Be Explained in Terms of Present Value Models?" Journal of Monetary Economics 30(1): 25-46.

- Fumiko Kon-ya, and Yoshiro TsuTsui. 1992. "Expanding the Scope of Expectations Data Collection: The U.S. and Japanese Stock Markets." Discussion Paper 1012. New Haven: Cowles Foundation, Yale University (March).

Siegel, Jeremy. 1992a. "The Equity Premium: Stock and Bond Returns Since 1802." Financial Analysts Journal, 28-38.

1992b. "The Real Rate of Interest from 1800-1990: A Study of the U.S. and the U.K." Journal of Monetary Economics 29(2): 227-52.

- 1994. Stocks for the Long Run. Irwin Professional Publishing (forthcoming).

Summers, Lawrence H. 1983. "The Nonadjustment of Nominal Interest Rates: A Study of the Fisher Effect." In Macroeconomics, Prices, and Quantities: Essays in Memory of Arthur M. Okun, edited by James Tobin. Washington: Brookings.

$\rightarrow$ Woodward, G. Thomas. 1990. "The Real Thing: A Dynamic Profile of the Term Structure of Real Interest Rates and Inflation Expectations in the United Kingdom, 1982-89." Journal of Business 63(3): 373-98.

$\longrightarrow \rightarrow$ 1992. "Evidence of the Fisher Effect from U.K. Indexed Bonds." Review of Economics and Statistics 74(2): 315-20. 